\title{
Cellulose Acetate Sulfate as a Lyotropic Liquid Crystalline Polyelectrolyte: Synthesis, Properties, and Application
}

\author{
D. D. Grinshpan, ${ }^{1}$ T. A. Savitskaya, ${ }^{1,2}$ N. G. Tsygankova, ${ }^{1}$ S. E. Makarevich, ${ }^{1}$ \\ S. M. Tretsiakova, ${ }^{3}$ and T. N. Nevar ${ }^{1}$ \\ ${ }^{1}$ Research Institute of Physical and Chemical Problems, Belarusian State University, Leningradskaya Street, 14, 220030 Minsk, Belarus \\ ${ }^{2}$ Science Chemistry Department, Belarusian State University, Leningradskaya Street, 14, 220030 Minsk, Belarus \\ ${ }^{3}$ The Built Environment Research Institute, School of the Built Environment, University of Ulster, Newtownabbey, BT37 0QB, UK
}

Correspondence should be addressed to T. A. Savitskaya, savitskayata@bsu.by

Received 13 July 2010; Accepted 14 November 2010

Academic Editor: Robert Shanks

Copyright (C) 2010 D. D. Grinshpan et al. This is an open access article distributed under the Creative Commons Attribution License, which permits unrestricted use, distribution, and reproduction in any medium, provided the original work is properly cited.

The optimal conditions of cellulose acetate sulfate (CAS) homogeneous synthesis with the yield of $94-98$ wt.\% have been determined. CAS was confirmed to have an even distribution of functional groups along the polymer chain. The polymer was characterized by an exceptionally high water solubility (up to $70 \mathrm{wt} . \%$ ). The isothermal diagrams of its solubility in water-alcohol media have been obtained. CAS aqueous solutions stability, electrolytic, thermal, and viscous properties have been defined. The main hydrodynamic characteristics such as intrinsic viscosity, Huggins constant, and crossover concentration have been evaluated. The parameters of polymer chain thermodynamic rigidity have been calculated. The formation of liquid crystalline structures in concentrated CAS solutions has been confirmed. CAS was recommended to be used as a binder for the medicinal forms of activated carbon and carbon sorbent for water treatment, hydrophilic ointment foundation.

\section{Introduction}

Synthesis, properties study, and application of polymer liquid crystals has recently become a promising trend in high molecular compounds chemistry. It has gained a great significance along with an intensive development of lowmolecular-weight liquid crystals science. Liquid crystalline (LC) polymers and their solutions have an immediate practical interest in industry of synthetic fibers-for manufacturing extra strong composite materials, in medicine and pharmacy - for design of drugs with improved bioactivity, in research studies-for modeling a series of processes occurring in living organisms. From this point of view, cellulose and its derivatives appear to be quite attractive objects. Cellulose derivatives such as hydroxypropyl cellulose; cellulose diacetate, triacetate, and acetate butyrate and so forth, are shown to experience the development of an LC order in the arrangement of the anisometric macromolecules in the presence of a relevant solvent at a certain critical polymer concentration. However, cellulose electrolytes have not been studied so far. Their macromolecules contain ionogenic groups that lead to an increased rigidity of polymer chain, and provide for their high solubility in aqueous media. Salts of cellulose mixed ester, cellulose acetate sulfate (CAS), can be related to this category of derivatives [1-5].

Presence of sulfate groups confers high hydrophilic properties to cellulose derivatives, and, therefore, they become soluble in water at degree of substitution (DS) as low as 0.40.6 [6]. Cellulose derivatives, having strong polyelectrolyte properties, can be prepared by the introduction of a greater amount of $\mathrm{HOSO}_{2} \mathrm{O}$ substituents. Whereas the presence of hydrophobic acetate groups together with evenly distributed along the cellulose chain sulfate groups should significantly increase thermodynamic rigidity of polymer chain. The latter is the main factor, determining the ability of a polymer to form LC structures in concentrated solutions. Neither the possibility of LC phase transition nor the rheological behavior of concentrated solutions have been studied for this type of polymers. 

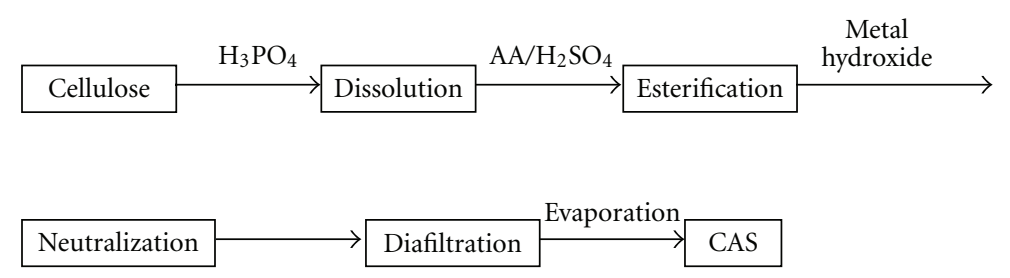

FIGURE 1: Scheme of homogeneous CAS synthesis

One of the main problems is to find unambiguous proofs of LC state formation, as quite often either induced anisotropy takes place, or nonequilibrium structures are observed, or not completely soluble fragments of polymer material are present in the solution. As there is a necessity to develop the concept that can predict whether a cellulose derivative is capable to form LC phase in its solution is of current interest. Therefore, the preparation of liquid crystals on the basis of water-soluble cellulose electrolyte, CAS, study of its properties in solid and soluble states, and the exploration of its application field are extremely important.

\section{Synthesis, Chemical Composition, and Structure of Cellulose Acetate Sulfate}

Traditionally CAS synthesis is performed as an esterification of cellulose in heterogeneous conditions. Processes of cellulose esterification in heterogeneous media are diffusioncontrolled. They generally occur when the rate of regents' penetration inside the cellulose fiber is less than the rate of the chemical reaction $[7,8]$. This leads to the preparation of derivatives with different esterification degree; as a result, the mixture of partially substituted and initial cellulose is formed [7].

Recent studies have been focused on the search for cellulose solvents suitable for conducting genuine homogeneous reactions that initiate and end in the solution [9]. The main feature of the products synthesized this way is their high homogeneity in both chemical composition and properties. It is justified as the morphological structure of the fiber is completely destroyed upon dissolution. Therefore, the diffusion rate of the reagents to macromolecules is the same [8]. The functionalization pattern of cellulose chain can be deliberately changed by conducting of esterification reactions in the solution. For instance, a certain functional group may be introduced in the exact position within glucopyranose unit (GPU), the final degree of substitution (DS) and the substituents distribution inside the elementary unit can be monitored, and the combination of different substituents along the length of macromolecules can be achieved. Subsequently, this gives an opportunity to prepare mixed cellulose esters featuring a range of valuable properties like stereoregularity, chirality, high hydrophilicity, and an ability to form well-ordered structures. From this point of view, chemical modification of cellulose by means of simultaneous introduction into its chain of the required amount of sulfate and acetate substituents is highly interesting to investigate.
Sulfite, sulfate, and cotton cellulose with a polymerization degree of 560, 1000 and 1200, respectively, were used as the initial material. All chemicals for CAS synthesis were analytically grade. Orthophosphoric acid was used for the cellulose solution preparation. Sulfuric acid and acetic anhydride played the role of the sulfation and acetylation agents. Solid lithium, sodium, potassium, and calcium hydroxides have been utilized in the neutralization process. The degree of substitution for sulfate and acetate groups was, respectively, $0.9-1.0$ and $0.8-1.0$, and the polymer average viscosimetric molecular mass was 46000 .

Homogeneous process of CAS preparation includes the following stages: cellulose dissolution in orthophosphoric acid, esterification of dissolved cellulose by acetic anhydride (AA) and sulfuric acid (SA), neutralization of reaction mixture by alkaline or alkaline-earth metals hydroxides and finally isolation of pure CAS salt. The process scheme is shown in Figure 1.

Among numerous well-known "direct" and "indirect" cellulose solvents [10], the most suitable one to conduct homogeneous synthesis is orthophosphoric acid. The reasons being:

(i) orthophosphoric acid degrades cellulose less significantly, as compared to sulfuric or trifluoroacetic acid (TFAA) (cellulose hydrolysis occurs 1000 times slower),

(ii) cellulose solutions in orthophosphoric acid are not air and light sensitive,

(iii) dissolution occurs very fast with formation of clear translucent solutions,

(iv) orthophosphoric acid is low toxic.

The dissolution of cellulose in orthophosphoric acid has been performed following a procedure described in [10] that allowed obtaining solutions with concentration from 6 to $12 \mathrm{wt} \% \%$ (depending on a molecular weight of initial cellulose material).

Following the esterification the obtained CAS solution has been neutralized by aqueous alkaline solutions of $\mathrm{LiOH}$, $\mathrm{NaOH}, \mathrm{KOH}$, or $\mathrm{Ca}(\mathrm{OH})_{2}$ up to $6.0-7.0 \mathrm{pH}$, and finally translucent solutions of $\mathrm{Li}^{-}, \mathrm{Na}-, \mathrm{K}-$, and $\mathrm{Ca}-$ salts of CAS have been formed. It is worth noting, that when the esterification and neutralization processes have been completed the weight of nonreacted cellulose particles was less than $5 \%$ from the weight of the initial cellulose material. Further, the neutralized CAS solution has been purified and concentrated by ultrafiltration. CAS in a solid state has been 
TABLE 1: Effect of the esterification mixture components volume ratio (AA/SA) on the main CAS characteristics.

\begin{tabular}{|c|c|c|c|c|c|c|}
\hline \multirow{2}{*}{ Volume ratio AA/SA } & \multicolumn{2}{|c|}{ Content of “combined" acids, wt.\% } & \multicolumn{2}{|c|}{ Degree of substitution } & \multirow{2}{*}{$V, \mathrm{~mm}^{2} / \mathrm{s}$} & \multirow{2}{*}{ Yield, wt.\% } \\
\hline & $\mathrm{A}_{\mathrm{Ac}}$ & A Sulf $_{1}$ & $\mathrm{DS}_{\mathrm{Ac}}$ & $\mathrm{DS}_{\text {Sulf }}$ & & \\
\hline $10: 0.2$ & 21 & 21 & 0.8 & 0.5 & Solution is not formed & $5 \pm 3$ \\
\hline $10: 0.5$ & 22 & 32 & 1.0 & 0.9 & 4.7 & $51 \pm 5$ \\
\hline $10: 1$ & 18 & 32 & 0.8 & 0.9 & 2.8 & $95 \pm 5$ \\
\hline $7: 1$ & 17 & 33 & 0.7 & 0.9 & 3.0 & $85 \pm 5$ \\
\hline $5: 1$ & 10 & 33 & 0.4 & 0.8 & 3.1 & $35 \pm 3$ \\
\hline $4: 1$ & 10 & 29 & 0.4 & 0.7 & 4.4 & $29 \pm 3$ \\
\hline
\end{tabular}

Note: Esterification duration is 2 hours.

isolated by evaporation of water on a rotary evaporator. The ready polymer film has been mechanically ground up to a powder, and practical yield of the final product has been determined.

Optimal conditions of cellulose homogeneous esterification have been established for Na-CAS preparation. For that purpose, an effect of series of factors like raw cellulose origin, volume ratio of acetic anhydride to sulfuric acid (AA/SA) and duration of esterification on the degree of substitution $\left(\mathrm{DS}_{\mathrm{Ac}}\right.$ and $\left.\mathrm{DS}_{\text {Sulf }}\right)$, kinematic viscosity of $1 \mathrm{wt} \%$. CAS solutions $(V)$ and the yield of final product have been studied. As it follows from Table 1, five-time increase of sulfuric acid volume content in the esterification mixture causes only a slight change of $\mathrm{DS}_{\mathrm{Ac}}$ (which stays in the interval of $0.8-$ $1.0)$, while $D S_{\text {Sulf }}$ values are practically doubled. The use of small amounts of sulfuric acid is preferable as it allows keeping the polymer chain as long as possible. However, herewith the yield of water soluble product of the reaction becomes very low (does not exceed 6 wt.\%). The increase of AA content in the esterification mixture causes an expected increase of the degree of acetylation $\mathrm{DS}_{\mathrm{Ac}}$ (from 0.4 to 0.8 ), while $D_{\text {Sulf }}$ rises very slightly (from 0.7 to 0.9 ) and the yield of CAS increases three-fold (more than $90 \mathrm{wt} . \%$ ). Thus, the optimal composition of the esterification mixture (AA/SA), that provides CAS preparation with the maximal yield and $D_{S_{\mathrm{Ac}}}=\mathrm{DS}_{\text {Sulf }}=0.8-1.0$, has been established experimentally.

It should be mentioned, that at the stage of cellulose dissolution the esterification of cellulose with orthophosphoric acid almost does not occur: the content of "combined" orthophosphoric acid was less than $0.5 \mathrm{wt} . \%$ in all obtained CAS samples.

The origin of raw cellulose material practically does not affect the final CAS degree of sulfation $\left(\mathrm{DS}_{\text {Sulf }}=0.8-0.9\right)$, while its degree of acetylation $\mathrm{DS}_{\mathrm{Ac}}$ has a tendency to decrease when moving from sulfite cellulose $\left(\overline{D P_{\eta}} 560\right)$ to sulfate cellulose $\left(\overline{D P_{\eta}} 1000\right)$ and, finally, to cotton cellulose $\left(\overline{D P_{\eta}} 1200\right)$. Meanwhile, values of the kinematic viscosity of $1 \mathrm{wt} . \% \mathrm{Na}$-CAS solutions increase as a degree of polymerization $\overline{D P_{\eta}}$ of cellulose material rises.

The study of kinetic aspects of the homogeneous esterification showed that in the first moments of the synthesis the sulfate of cellulose predominantly takes place (Figure 2). Indeed, 40 minutes after the esterification started $\mathrm{DS}_{\text {Sulf }}$ was approximately ten times higher than $\mathrm{DS}_{\mathrm{Ac}}$. Though,

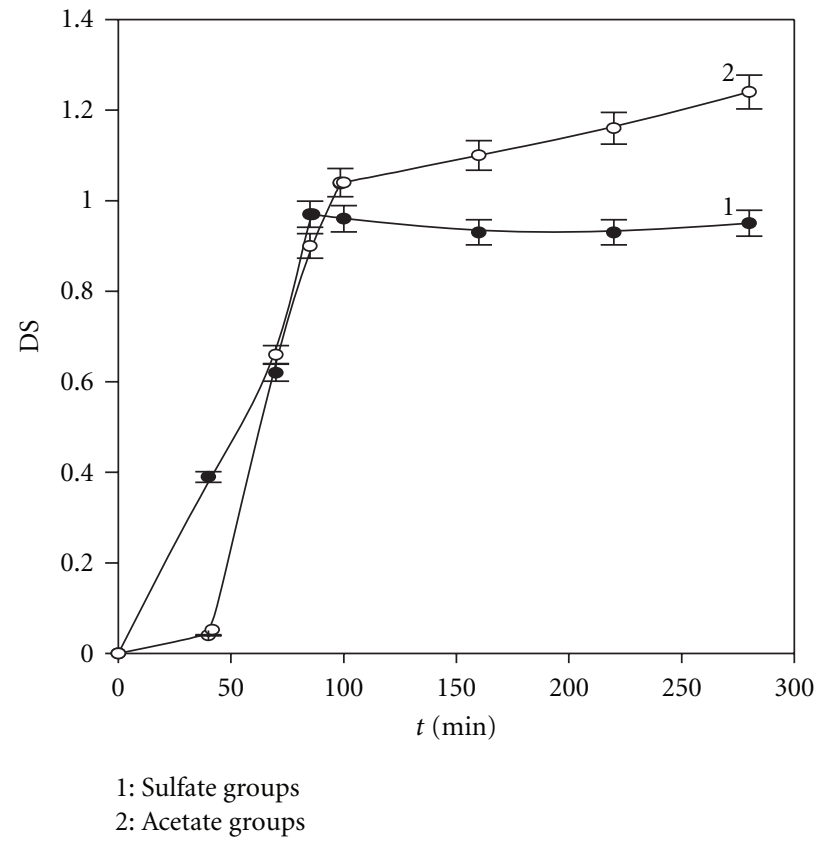

Figure 2: Curves of functional groups accumulation in the polymer at the homogeneous synthesis of CAS.

the rate of acetylation equals the rate of sulfation after 70 minutes after the reaction began. Esterification duration of 100 minutes is critical as it corresponds to the moment of nearly bisubstituted cellulose derivative formation $\left(\mathrm{DS}_{\mathrm{Ac}}+\right.$ $\left.\mathrm{DS}_{\text {Sulf }}=1.8-2.0\right)$.

Due to the following course of the reaction, DS Sulf $_{\text {stays }}$ practically constant $(0.9-1.0)$ and $\mathrm{DS}_{\mathrm{Ac}}$ gradually increases up to 1.2 .

Based on the above-described data, the following scheme of the reaction can be suggested. At first, esterification of cellulose with the sulfuric acid takes place

$$
\begin{aligned}
& {\left[\mathrm{C}_{6} \mathrm{H}_{7} \mathrm{O}_{2}(\mathrm{OH})_{3}\right]_{n}+n x \mathrm{H}_{2} \mathrm{SO}_{4}} \\
& \quad \longrightarrow\left[\mathrm{C}_{6} \mathrm{H}_{7} \mathrm{O}_{2}(\mathrm{OH})_{3-x}\left(\mathrm{OSO}_{2} \mathrm{OH}\right)_{x}\right]_{n}+n x \mathrm{H}_{2} \mathrm{O}
\end{aligned}
$$

Then, AA reacts with water, contained in the system

$$
\left(\mathrm{CH}_{3} \mathrm{CO}\right)_{2} \mathrm{O}+\mathrm{H}_{2} \mathrm{O} \longrightarrow 2 \mathrm{CH}_{3} \mathrm{COOH} \text {. }
$$


TABLE 2: The location of signals from carbon nuclei atoms in $\mathrm{NMR}{ }^{13} \mathrm{C}$ spectra of cellulose and its derivatives.

\begin{tabular}{lccccc}
\hline \multirow{2}{*}{ Cellulose derivative } & \multicolumn{5}{c}{ Chemical shift $\delta, \mathrm{ppm}$} \\
& $\mathrm{C}_{1}$ & $\mathrm{C}_{2} \mathrm{C}_{3} \mathrm{C}_{5}$ & $\mathrm{C}_{4}$ & $\mathrm{C}_{6}$ & $\mathrm{C}_{7}(\mathrm{C}=\mathrm{O})$ \\
\hline $\mathrm{Na}-\mathrm{CS}\left(\mathrm{DS}_{\text {Sulf }}=1.0\right)$ & $101.5 ; 99.5$ & $74.5-72.5$ & $77.5 ; 79.0$ & $69.0 ; 66.5 ; 60.5$ & - \\
$\mathrm{CA}\left(\mathrm{DS}_{\mathrm{Ac}}=0.8\right)$ & $101.5 ; 99.5$ & $74.5-72.5$ & 78.5 & $62.5 ; 60.0$ & $170.0 ; 169.8$ \\
$\mathrm{Na}-\mathrm{CAS}\left(\mathrm{DS}_{\mathrm{Ac}}=\mathrm{DS}_{\text {Sulf }}=1.0\right)$ & 98.7 & $74.0-72.0$ & 76.5 & $64.5 ; 60.0$ & $21.4 ; 22.0$ \\
Cellulose i crystalline [8] & 105.0 & $75.0-71.8$ & $89.0 ; 84.0$ & $65.0 ; 62.5$ & 21.4 \\
Cellulose amorphous [8] & 104.5 & 75.0 & 84.0 & 62.5 & - \\
\hline
\end{tabular}

As a result, equilibrium of the reaction (1) shifts to the right and sulfuric acid fast and practically fully combines with cellulose. After that, the acetylation begins

$$
\begin{aligned}
& {\left[\mathrm{C}_{6} \mathrm{H}_{7} \mathrm{O}_{2}(\mathrm{OH})_{3-x}\left(\mathrm{OSO}_{2} \mathrm{OH}\right)_{x}\right]_{n}+n y \mathrm{CH}_{3} \mathrm{COOH}} \\
& \longrightarrow\left[\mathrm{C}_{6} \mathrm{H}_{7} \mathrm{O}_{2}(\mathrm{OH})_{3-x-y}\left(\mathrm{OSO}_{2} \mathrm{OH}\right)_{x}\left(\mathrm{OCOCH}_{3}\right)_{y}\right]_{n} \\
& +n y \mathrm{H}_{2} \mathrm{O}
\end{aligned}
$$

According to the chemical analysis data, Na-CAS prepared in the homogeneous media at optimal conditions, mentioned above, contains approximately 17-19wt.\% of "combined" acetic acid and 32-35wt.\% of "combined" sulfuric acid. Thus, the composition of Na-CAS elementary repeated unit can be represented as the following:

$$
\begin{gathered}
{\left[\mathrm{C}_{6} \mathrm{H}_{7} \mathrm{O}_{2}(\mathrm{OH})_{(1.0-1.4)}\left(\mathrm{OCOCH}_{3}\right)_{(0.8-1.0)}\right.} \\
\left.\cdot\left(\mathrm{OSO}_{2} \mathrm{ONa}\right)_{(0.8-1.0)}\right]_{n}
\end{gathered}
$$

In order to determine functional groups distribution pattern within the elementary unit of homogeneously synthesized Na-CAS $\left(\mathrm{DS}_{\mathrm{Ac}}=\mathrm{DS}_{\text {Sulf }}=1.0\right) \mathrm{NMR}{ }^{13} \mathrm{C}$ spectra of its samples, dissolved in $\mathrm{D}_{2} \mathrm{O}$, have been recorded. The NMR ${ }^{13} \mathrm{C}$ spectra were written with a TESLA BS $587 \mathrm{~A}$ spectrometer operating at 20,182 MHz. Chemical shifts were determined according to $\mathrm{CD}_{3} \mathrm{OD}$ signal (49.3 ppm). These spectra have been compared to the ones recorded for CA $\left(\mathrm{DS}_{\mathrm{Ac}}=0.8\right)$ and $\mathrm{Na}-\mathrm{CS}\left(\mathrm{DS}_{\text {Sulf }}=1.0\right)$, prepared in heterogeneous conditions according to procedures described in [11] and [12], respectively.

Interpretation of signals from ${ }^{13} \mathrm{C}$ nuclei atoms within elementary units of the cellulose derivatives has been performed by comparing their spectra with the ones for crystalline and amorphous cellulose [13], and also by comparing them with spectral characteristics of CA and CS referred in the literature [14-17]. The most possible assignment of chemical shifts from ${ }^{13} \mathrm{C}$ nuclei for all cellulose derivatives studied is represented in Table 2.

Atoms $\mathrm{C}_{1}$ signals in the spectra of soluble CA, Na-CS, and Na-CAS samples, compared to the ones for nonsoluble sample of cellulose I, move up field from 105.0 to 101.5-98.7 ppm, that is significantly bigger then signal shift occurring upon amorphization of cellulose (to $104.5 \mathrm{ppm}$ [8]). The largest up field shift has been observed in the Na-CAS spectrum: by more than $6 \mathrm{ppm}$ (to $98.7 \mathrm{ppm}$ ).
Also in the CA and $\mathrm{Na}$-CS spectra peak assigned to $\mathrm{C}_{1}$ atoms is split in two. Besides peaks from ${ }^{13} \mathrm{C}$ nuclei atoms of the GPU in the region of $\delta 102-60 \mathrm{ppm}$, signals from carbon atoms of carbonyl $\delta 170.5-169.0 \mathrm{ppm}$ have been registered in the Na-CAS and CA spectra. Doublet of signals from atoms ${ }^{13} \mathrm{C}$ of carbonyl and methyl groups in the CA spectra indicates that acetate groups are located at different position inside GPU. Bearing in mind relative reactivity of $\mathrm{OH}$ groups in acetylation reactions of cellulose [8], it could be expected that acetate groups are located mainly at $\mathrm{C}_{2}$ and partly at $\mathrm{C}_{6}$ position of the GPU of CA. In accordance with conceptions, regarding the impact of electronegative substituents on the peaks location in NMR ${ }^{13} \mathrm{C}$ spectra, an introduction of ester groups into cellulose macromolecules should cause downfield shift of signals from carbon atoms at $\mathrm{C}_{6}$ position of $\mathrm{GPU}$ as well [10]. Indeed, there are three peaks $\delta 69.0 ; 66.5$, and $60.5 \mathrm{ppm}$ in the Na-CS spectrum. Downfield shift of signals $\delta 69.0$ and $66.5 \mathrm{ppm}$ in relation to the peak from atoms at $\mathrm{C}_{6}$ in amorphous cellulose $(\delta 62.5 \mathrm{ppm})$ can be explained by strong deshielding effect of sulfate groups. Double signals have been registered in the spectra of CA and Na-CAS solutions: $\delta 62.5,60.0 \mathrm{ppm}$ and $64.5,60.0 \mathrm{ppm}$, respectively. Downfield signals $\delta 64.5$ and $62.5 \mathrm{ppm}$ can be explained by the esterification of hydroxyl groups at $\mathrm{C}_{6}$ position, while upfield signal $\delta 60.0 \mathrm{ppm}$ points out at the presence of unsubstituted primary $\mathrm{OH}$ groups in GPU.

Unfortunately, detailed interpretation of peaks in the chemical shift region of $72.0-74.5 \mathrm{ppm}$ is impossible as carbon atoms at $\mathrm{C}_{2}, \mathrm{C}_{3}$, and $\mathrm{C}_{5}$ positions of GPU give a complicated pattern of signals. Functional groups location and their distribution along the polymer chain length for prepared water soluble cellulose derivatives, with certain level of approximation, can be represented by model formulae (Figure 3).

Thus, the comparison of NMR ${ }^{13} \mathrm{C}$ spectra of lowsubstituted cellulose derivatives showed that in the homogeneously synthesized Na-CAS OH groups substitution occurs selectively, namely, sulfate group is predominantly located at $\mathrm{C}_{6}$ position, while acetate groups-at $\mathrm{C}_{2}$ position of GPU. For CS and CA, prepared in heterogeneous conditions, substituents distribution inside the elementary unit has a statistical character. The operation of synthesis in homogeneous media allows producing cellulose derivatives having the uniform functional groups distribution within their elementary units. 
$\mathrm{CA}\left(\mathrm{DS}_{\mathrm{Ac}}=0.8\right)$

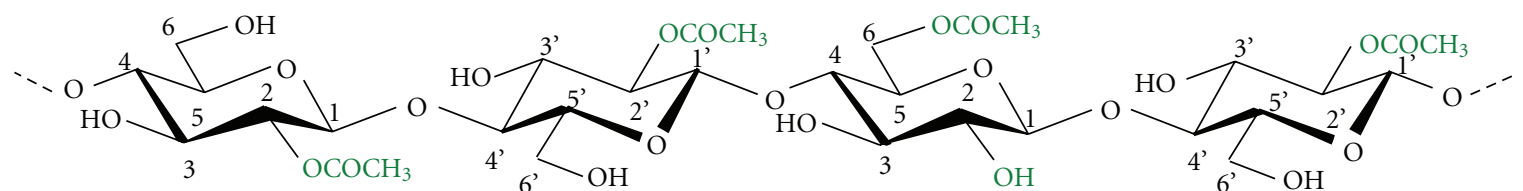

$\mathrm{Na}-\mathrm{CS}\left(\mathrm{DS}_{\text {Sulf }}=1\right)$

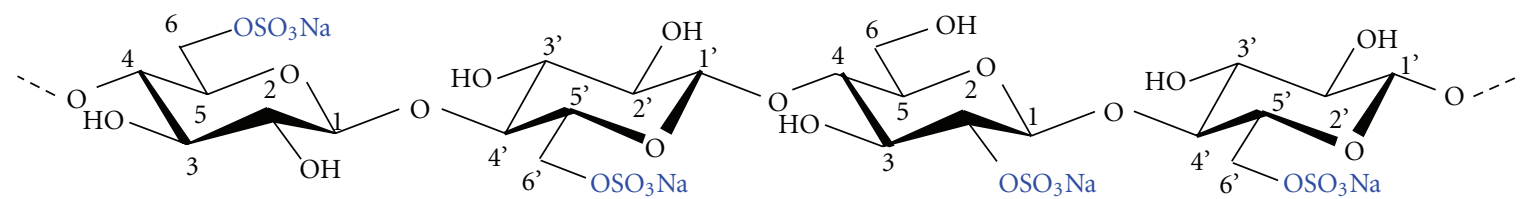

(6)

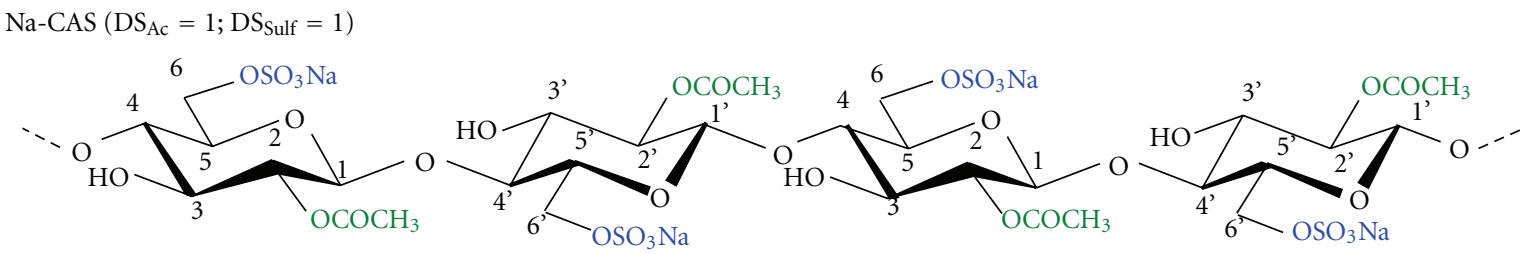

FIGURE 3: Representation of different cellulose derivatives polymer chains.

\section{Physical-Chemical Properties of Cellulose Acetate Sulfate Films and Solutions}

A considerable increase of reduced specific viscosity $\eta_{\mathrm{sp}} / c$ upon the solution dilution, so-called "polyelectrolyte swelling," was observed in the Na-CAS aqueous solutions.

Solutions of CAS salts were prepared gravimetrically by dissolving weighted polymer samples preliminarily dried to a constant weight at $60 \pm 2{ }^{\circ} \mathrm{C}$ in water, water-salt, and water-alcohol media at a different ratio of components. Concentrated solutions were deaerated for $48 \mathrm{~h}$. The viscosity of diluted solutions of CSA salts with the concentration of $1 \mathrm{~g} / 100 \mathrm{~cm}^{3}$ were measured at $25^{\circ} \mathrm{C}$ by an Ubbelode viscosimeter with the inner capillary diameter of $0.54 \mathrm{~mm}$. The characteristic viscosity was determined by the method of double extrapolation of the dependences $\eta_{\mathrm{sp}} / c=f(c)$ and $\ln \left(\eta_{\mathrm{rel}} / c\right)=f(c)$ to the zero concentration. The Huggins constant $k_{H}$ was calculated by the slop of the $\eta_{\mathrm{sp}} / c=f(c)$ curve and the crossover concentration $c^{*}$ — by the inflection of this curve.

Solution ionic strength increases by adding lowmolecular-weight electrolyte, sodium chloride leads to a decrease of repulsion of the like charges distributed along the length of the Na-CAS polymer chain, and hence causing a suppression of "polyelectrolyte swelling" at $\mathrm{NaCl}$ content of $0.2 \mathrm{M}$.

Upon a gradual increase of the Na-CAS content in aqueous solutions an inflection called crossover concentration

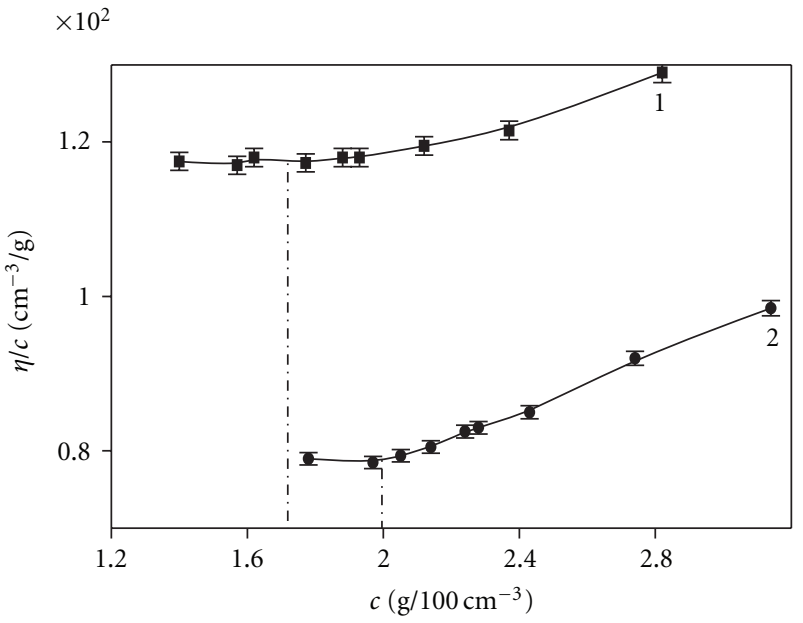

Figure 4: The plot of the reduced specific viscosity versus Na-CAS content in water (1) and $0.2 \mathrm{M} \mathrm{NaCl}$ solution (2).

appears on the dependences $\eta_{\mathrm{sp}} / c=f(c)$ at a concentration value $C_{\mathrm{cr}}$, (Figure 4 ). At this point a fluctuation engagement net is formed in the Na-CAS solution, and its flow regime abides by the laws relevant to semiconcentrated solutions [18].

The experimental $C_{\mathrm{cr}}$ values come to $1.70 \mathrm{~g} / 100 \mathrm{~cm}^{3}$ in water and $2.00 \mathrm{~g} / 100 \mathrm{~cm}^{3}$ in $0.2 \mathrm{M} \mathrm{NaCl}$ solution that is 
quite close to the ones calculated from viscosimetric Debye criterion [18]: $2.00 \mathrm{~g} / 100 \mathrm{~cm}^{3}$.

Owing to ionogenic $\mathrm{HOSO}_{2} \mathrm{H}$ groups presence in the polymer chain Na-CAS can be subsumed to the category of polymer acids. When H-CAS (Note- $\mathrm{H}$-CAS was prepared from $\mathrm{Na}$-CAS aqueous solution (concentration is $1 \mathrm{~g} / 100 \mathrm{~cm}^{3}$ ) by means of ion exchange resin KU-2.) contacts low-molecular-weight electrolyte its macromolecules exchange proton to a cation. Ion exchange has been used to prepare various CAS salts in the $\mathrm{pH}$ interval of $2-7$. It has been found, that CAS ion exchange capacity is $9 \mathrm{mmol} / \mathrm{g}$. The prepared polymer salts (Li-, Na-, K-, Ca-, Mg-, Zn-, and CoCAS) were completely soluble in water and in the aqueous solutions of acids, alkaline, and inorganic salts. As the ionic radius of compensating counter-ion increases solution concentration values $C_{\max }$, corresponding to the maximal CAS salts solubility in water decrease in the following order:

$$
\begin{gathered}
\text { Li-CAS }>\text { Na-CAS }>\text { Ca-CAS }>\text { K-CAS } \\
=70>60>55>52 \text { wt. } \% .
\end{gathered}
$$

These salts were not soluble in the individual organic solvents such as mono-, di-, and polyhydric alcohols, ethers, esters, ketones, carbonic acids, and their amides. Although, polymer had swollen and finally formed genuine solutions when above-mentioned solvents were mixed with water.

It has been found that CAS aqueous solutions are not visually transparent at concentrations higher than $C_{\mathrm{cr}}$.

This suggests that there is the association of macromolecules without the formation of a certain order in their arrangement. Highly concentrated (over $35 \mathrm{wt} . \%$ ) aqueous solutions of CAS salts, excluding K-CAS, have displayed stable birefringence. In a stationary state and upon flowing, these solutions were opalescent, changing their colour from yellow-red to violet, which is indicative of the cholesteric mesophase formation [19-21]. However, this phenomenon only indirectly confirms the LC order formation in the CAS solutions. Bearing in mind high values of the CAS solutions viscosity, according to [22], the birefringence can be caused either by the forced macromolecules orientation or by the presence of partially soluble particles in the solution, but not as a result of spontaneous LC transition of the polymer. More reliable results can be obtained using rheology and polarized optical microscopy $[23,24]$. Therefore, we have conducted a complex of polarizing microscopic and rheological examinations of the Na-CAS solutions in the 42-58 wt.\% concentration range and within the temperature interval of $20-50^{\circ} \mathrm{C}$. The rheological characteristics of CAS solutions were measured by "Rheotest-2" rotational viscometer with a cylinder-cylinder working unit in the shear stress range from 1.6 to $3.0 \mathrm{~Pa}$ at $20-50^{\circ} \mathrm{C}$.

Based on the rheological studies of the Na-CAS solutions, the viscosity versus concentration dependence, shown on Figure 5, had an extremum typical for LC systems $[23,24]$. The viscosity maximum has been registered at the polymer concentration of $52 \mathrm{wt} . \%$. The association of macromolecules although without a certain order in their arrangement can be viewed as a probable cause. The height of the maximum decreases as a shear rate increases, indicating

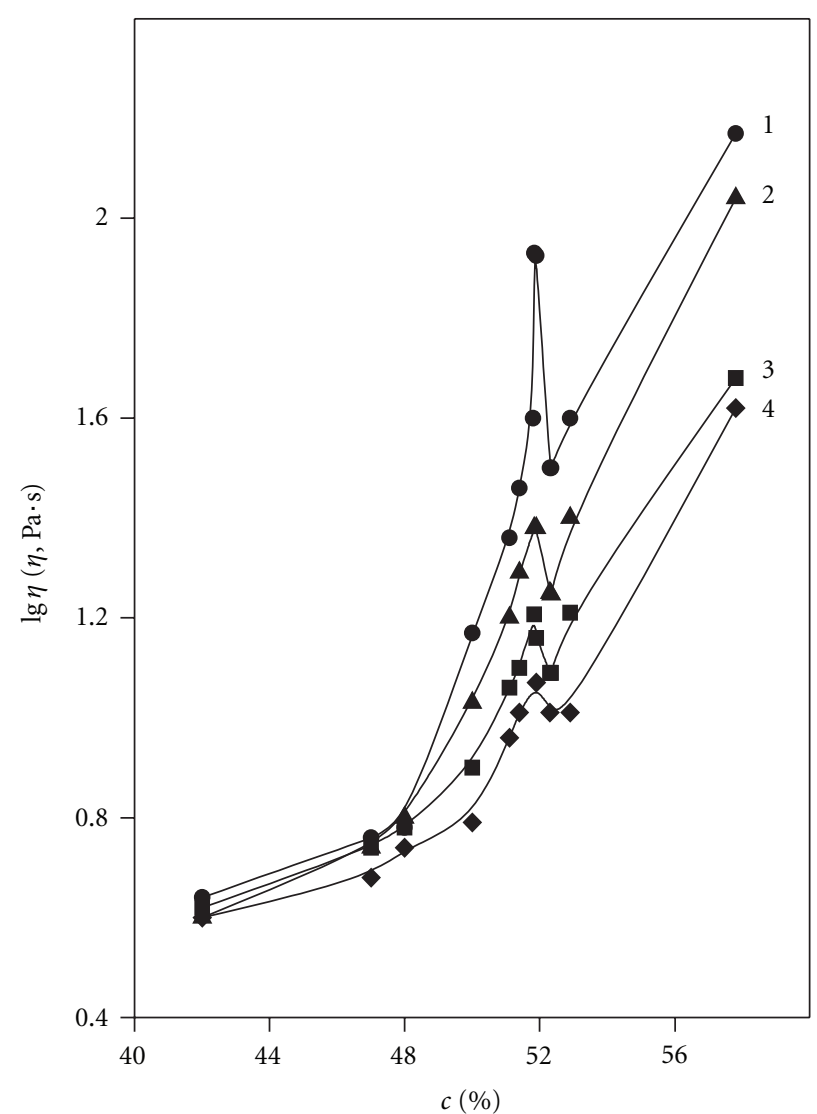

Figure 5: Viscosity versus concentration for aqueous Na-CAS solutions at shear stress $\tau$ : 1: $25 \mathrm{~Pa} ; 2: 40 \mathrm{~Pa} ; 3: 250 \mathrm{~Pa}$;: $660 \mathrm{~Pa}$ $\left(T=20^{\circ} \mathrm{C}\right)$

both the breakdown of LC domains in the Na-CAS solutions under this type of external action on the system and the spontaneous ordering of polymer macromolecules in the solution in the absence of the deformation.

In concentrated $\mathrm{Na}$-CAS solutions (over $42 \mathrm{wt} . \%$ ) ordered structures distributed in an isotropic medium in the form of individual spherulites between 10 to $50 \mathrm{~nm}$ in diameter have been clearly recorded (Figure 6(a)). With increasing content of the polymer in the solution, the spherulites aggregate in the form of bands and more complex structural formations (Figure 6(b)). Microheterogeneous systems containing such spherulites are thermodynamically unstable, and storing them for 1 month at $5^{\circ} \mathrm{C}$ leads to a clear separation of the solution into transparent and turbid layers, which corresponds, to the structure, to the isotropic, and anisotropic phases.

The viscosity maximum, registered at the polymer concentration of $52 \mathrm{wt} . \%$, characterizes the moment when the inversion of iso- and anisotropic phase takes place, and the $\mathrm{Na}$-CAS solutions become the LC matrix containing smallsized regions of isotropic inclusions (Figure 6(c)), which completely disappear with solution concentration further increase. At concentration of more than $52.5 \mathrm{wt} . \%$, the NaCAS solution is completely anisotropic (LC) and the viscosity 


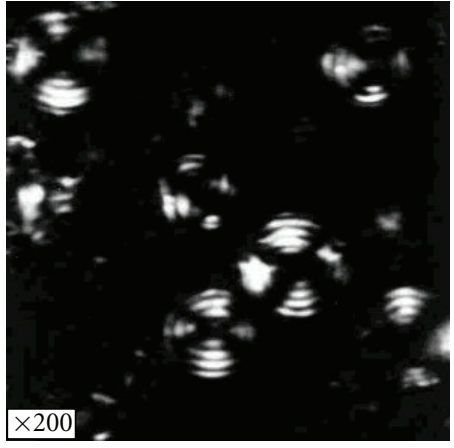

(a)

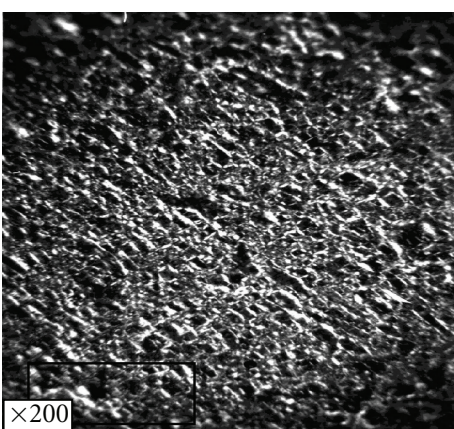

(d)

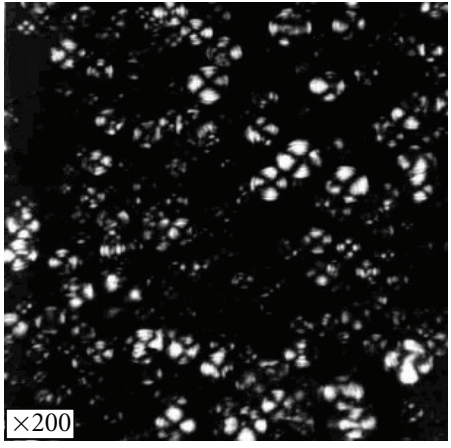

(b)

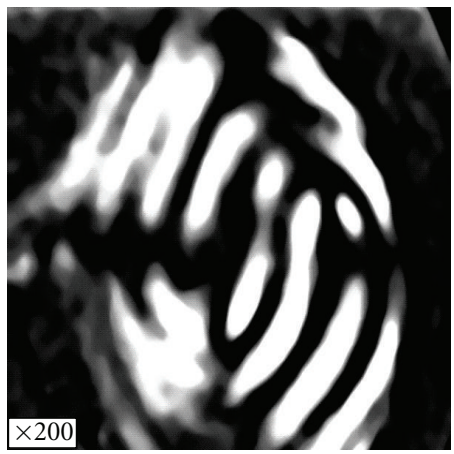

(e)

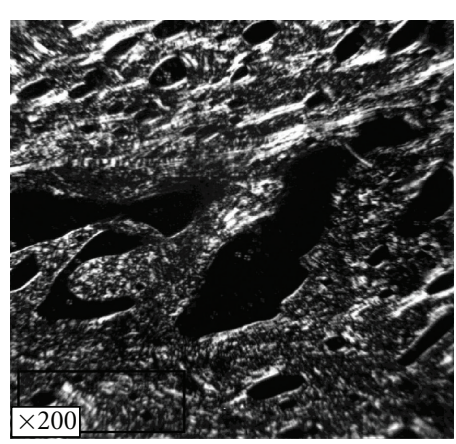

(c)

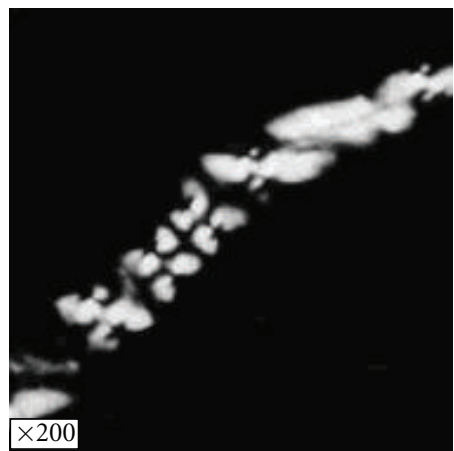

(f)

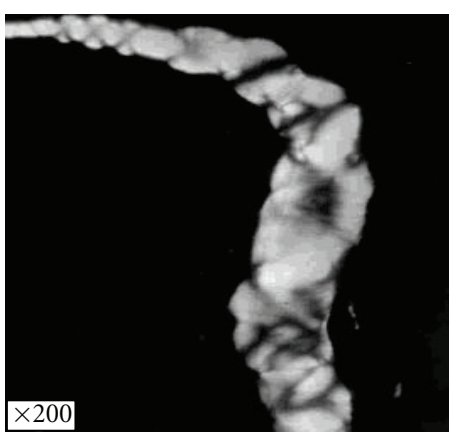

(g)

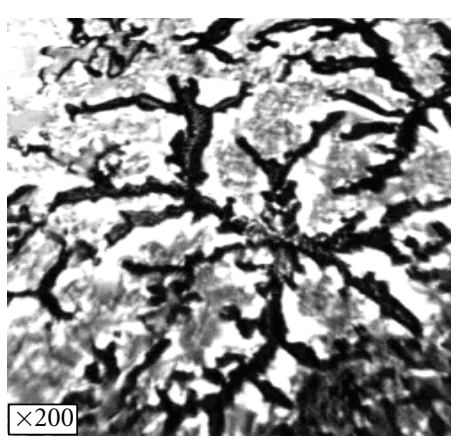

(h)

FIgURE 6: Microphotographs of the structures arising in aqueous solutions of CAS at $20^{\circ} \mathrm{C}$.

rises again. In this case, the corresponding microscopic image of the solution shows a confocal texture (Figure 6(d)), which is transformed into a planar one upon shearing [25].

Moreover, in the range of concentration between 50 and 52 mass $\%$, we have registered a texture of fingerprints typical for cholesteric liquid crystals (Figure 6(e)).

Similar phase transformations are also characteristic of Li-, Ca-, Mg-, Zn-, and Co-CAS. As for calcium salt of CAS the formation of structures of the shish-kebab type (Figures 6(f) and 6(g)) and dendritic structures (Figure 6(h)) have also been noticed. Whereas for the K-CAS solutions, none of the rheological signs of the LC transition have been found. The character of the K-CAS solutions flow upon shear was practically Newtonian: its flow curves had no dynamic yield point (Figures 7 and 3), and there were no extremums on the concentration and temperature dependences of the viscosity. Unlike the $\mathrm{Li}^{-}, \mathrm{Na}-$, , and $\mathrm{Ca}-\mathrm{CAS}$, the K-CAS solutions were single-phased and isotropic: the formation of ordered supramolecular structures has not been found in polarized light throughout whole concentration range studied (up to $52 \mathrm{wt} \%$ ). "Amplival" (Germany) optical microscope equipment with polaroids was used for the observation of a thin polymer solution layer.

3.1. Thermal Properties of Cellulose Acetate Sulfate Films and Solutions. The transition of the CAS in to the LC state is a first-order phase transition, described by the strictly distinct concentration and temperature parameters [23]. Unfortunately, the precise estimation of the temperature corresponding to LC phase melting in the CAS solutions 
TABLE 3: Thermal characteristics of film specimens of the CAS salts.

\begin{tabular}{|c|c|c|c|c|c|c|c|c|c|c|c|c|c|}
\hline \multirow{2}{*}{$\begin{array}{l}\text { Counter-ion } \\
\text { (cation) }\end{array}$} & \multirow{2}{*}{$\begin{array}{l}\text { Volume of } \\
\text { hydrated cation } \\
\bar{V}_{\text {hydr }} \mathrm{cm}^{3} / \mathrm{mol} \\
{[22]}\end{array}$} & \multirow{2}{*}{$\begin{array}{l}\text { Hydration } \\
\text { number } n \\
{[22]}\end{array}$} & \multicolumn{5}{|c|}{ endothermic effect } & \multicolumn{4}{|c|}{ exothermic effect } & \multirow{2}{*}{$\mathrm{T}_{20 \%},{ }^{\circ} \mathrm{C}$} & \multirow{2}{*}{$T_{40 \%},{ }^{\circ} \mathrm{C}$} \\
\hline & & & $T_{i},{ }^{\circ} \mathrm{C}$ & $T_{p},{ }^{\circ} \mathrm{C}$ & $T_{f},{ }^{\circ} \mathrm{C}$ & $d m, \%$ & $\begin{array}{c}E_{a}, \\
\mathrm{~kJ} / \mathrm{mol}\end{array}$ & $T_{i},{ }^{\circ} \mathrm{C}$ & $T_{p},{ }^{\circ} \mathrm{C}$ & $T_{f},{ }^{\circ} \mathrm{C}$ & $d m, \%$ & & \\
\hline $\mathrm{Ca}^{2+}$ & 156.7 & 10 & 20 & 85 & 180 & 15 & 19.7 & 210 & 250 & 255 & 23 & 245 & 267 \\
\hline $\mathrm{Li}^{+}$ & 125.9 & 8 & 22 & 85 & 160 & 18 & 24.1 & 182 & 197 & 237 & 35 & 177 & 187 \\
\hline $\mathrm{Na}^{+}$ & 109.0 & 6 & 25 & 87 & 180 & 15 & 16.5 & 185 & 212 & 220 & 29 & 205 & 225 \\
\hline \multirow{2}{*}{$\mathrm{K}^{+}$} & \multirow[b]{2}{*}{94.4} & \multirow[b]{2}{*}{5} & \multirow[b]{2}{*}{30} & \multirow[b]{2}{*}{95} & \multirow[b]{2}{*}{165} & \multirow[b]{2}{*}{15} & \multirow[b]{2}{*}{15.1} & 207 & 215 & 225 & 11 & \multirow[b]{2}{*}{215} & \multirow[b]{2}{*}{257} \\
\hline & & & & & & & & 232 & 250 & 255 & 16 & & \\
\hline
\end{tabular}

with the aid of rheological method and polarized optical microscopy appeared to be difficult. Therefore to resolve this issue it was suggested to use a combination of thermal methods (such as TG, DTG, DTA, and DSC) to CAS solutions and films analysis. Thermoanalytical studies of CAS salts films were made with the use of Netzsch STA 449C thermoanalyzer (TG, DTG, and DTA) in the temperature range of $15^{\circ}$ to $600^{\circ} \mathrm{C}$ and of CAS solutions with the help of thermoanalyser "Mettler system FP 90" with attachment Mettler FP 85 (DSC) of $15^{\circ}$ to $60^{\circ} \mathrm{C}$. CAS films were prepared by spreading a concentrated solutions (42-58 mass\%) over the smooth surface with the subsequent evaporation of water in the air. The films were conditioned in the exsiccator with $\mathrm{CaCl}_{2}$ before measuring.

The behavior of the CAS ionic forms upon heating appeared to be different. For instance, while isolating the $\mathrm{H}$-CAS by freeze-drying it has been found that the intense process of polymer chains degradation and hydrolysis of its ester bonds begins at as low a temperature as $10^{\circ} \mathrm{C}$. Consequently, the preparation of $\mathrm{H}$-CAS in the solid form was not practically feasible. In similar conditions CAS containing alkaline and alkaline-earth metal ions as compensating counter-ions turned out to be significantly more stable than its acidic form. Since the DTA curves displayed a number of overlapping effects that are difficult to resolve, we have used TGA and DTG curves to estimate thermal stability of different CAS salts. The characteristics of the curves are given in Table 3.

When the film samples of $\mathrm{Li}, \mathrm{Na}, \mathrm{K}$, and Ca-CAS were heated at the rate of $5^{\circ} \mathrm{C} / \mathrm{min}$ in the temperature range of $15-300^{\circ} \mathrm{C}$, a decrease in sample mass $(\mathrm{dm})$ has been found at as low as $20-30^{\circ} \mathrm{C}\left(T_{i}\right)$. On further heating, an endothermic peak with the maximum rate of mass loss at $85-95^{\circ} \mathrm{C}\left(T_{p}\right)$, which ended at $160-180^{\circ} \mathrm{C}\left(T_{f}\right)$, has been observed. The actual mass losses accompanying this process came to $15-18$ wt.\%, which markedly exceed the values of relative humidity of films (10-12 wt.\%). It is quite likely that in this temperature interval not just the removal of moisture sorbed by the surface of polymer specimen but also processes resulting in the removal of co-called "nonfreezing" water from the cations' vicinity take place. We have estimated the effective values of the activation energy $E_{a}$ of the latter process using the Freeman-Carol method [26]. The calculated activation parameters results (Table 3 ) show that $E_{a}$ values consistently decrease from the lithium to potassium

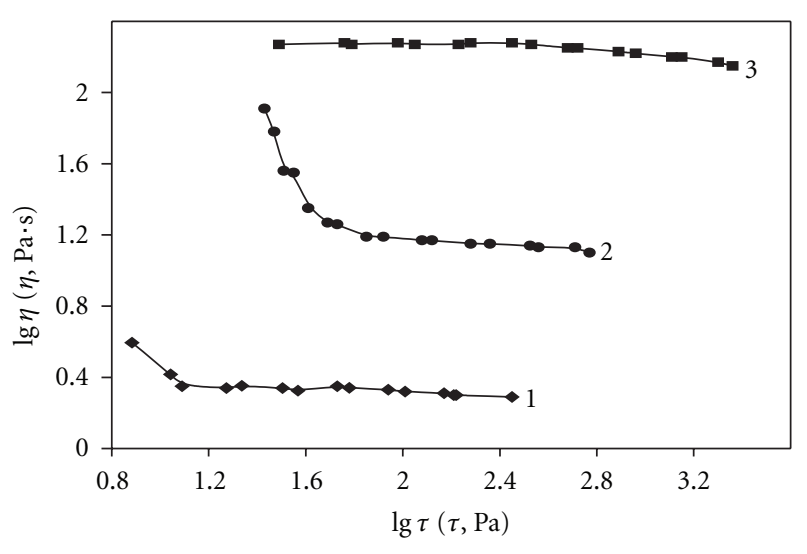

$$
\begin{aligned}
& \text { 1: Li-CAS } \\
& \text { 2: Na-CAS } \\
& \text { 3: K-CAS }
\end{aligned}
$$

FIGURE 7: Plot of the viscosity of $52 \mathrm{wt} . \%$ aqueous CAS salts solutions versus shear stress $\left(T=20^{\circ} \mathrm{C}\right)$.

salt of CAS, which correlates with a decrease in the degree of cations hydration in the following series: $\mathrm{Li}^{+}>\mathrm{Na}^{+}>\mathrm{K}^{+}$ [27, 28].

On further heating in the range of $160-300^{\circ} \mathrm{C}$, the second process of mass loss accompanied by heat release (exothermic effect) has been detected, that may be explained by the thermooxidative degradation of polymer chain and the formation of low-molecular-weight oxidation products.

From data represented in Table 3 , it follows that the temperatures of the maximum rate of mass loss $\left(T_{p}\right)$ and the temperatures of 20 and $40 \%$ mass loss $\left(T_{20 \%}\right.$ and $T_{40 \%}$ ) consistently increase from the lithium to the sodium, potassium, and finally calcium form of CAS. It appears that K-CAS and Ca-CAS specimens have the highest stability against oxidation and degradation. It should be noted that while heating the K-CAS not just one but two exothermic peaks $\left(T_{p}=215^{\circ} \mathrm{C}\right.$ and $\left.T_{p}=250^{\circ} \mathrm{C}\right)$ have been registered.

The Kuhn segment length $A$ and axial ratio $x$, representing the degree of chain anisodiametry, are quantitative characteristics of the thermodynamic rigidity of macromolecules. The latter has been calculated for the different CAS salts in accordance with [29]. This allowed us to estimate the critical concentration of polymer LC ordering in the solution 
TABLE 4: Calculated and experimental values of critical LC transition concentration for different CAS salts.

\begin{tabular}{lcccccc}
\hline $\begin{array}{l}\text { Counterion } \\
\text { (cation) }\end{array}$ & $\begin{array}{l}C_{\max }, \\
\text { wt.\% }\end{array}$ & $A, \AA$ & $X$ & $\varphi_{\text {2calc }}$ & $\begin{array}{c}C_{\text {calc, }}^{*} \\
\text { wt.\% }\end{array}$ & $\begin{array}{c}C_{\text {calc, }}^{*} \\
\text { wt.\% }\end{array}$ \\
\hline $\mathrm{Li}^{+}$ & 70 & 200 & 26.7 & 0.28 & 39 & 35 \\
$\mathrm{Na}^{+}$ & 60 & 220 & 28.5 & 0.26 & 37 & 42 \\
$\mathrm{Ca}^{2+}$ & 55 & 240 & 29.5 & 0.25 & 36 & 30 \\
$\mathrm{~K}^{+}$ & 52 & 120 & 15.8 & 0.44 & 57 & $\begin{array}{c}\text { not } \\
\text { detected }\end{array}$ \\
\hline
\end{tabular}

$\left(\varphi_{2 \text { calc }}\right.$ and $\left.C_{\text {calc }}^{*}\right)$ using the Flory equation $[24,30]$ (Table 4). A quite satisfactory correlation between values of the theoretically calculated $\left(C_{\text {calc }}^{*}\right)$ and experimental $\left(C_{\text {exp }}^{*}\right)$ concentrations, corresponding to the initial mesophase emergence in concentrated $\mathrm{Li}, \mathrm{Na}$, and $\mathrm{Ca}-\mathrm{CAS}$ solutions, has been obtained. At the same time, as mentioned above, LC order did not occur in concentrated K-CAS solutions.

Herewith, among all CAS salts studied only K-CAS is characterized by the following:

(i) the absence of birefringence in concentrated solutions,

(ii) the relatively low solubility in water, compared to the other salts (Table 4),

(iii) the low values of polymer chain thermodynamic rigidity (Table 4 ),

(iv) the Newtonian-type character of the solution flow (Figure 5),

(v) the absence of extremum points at concentration and temperature,

(vi) dependencies of shear viscosity,

(vii) the absence of any optical signs of the ordered structures formation even at the highest possible solution concentration $\left(C_{\max }=52 \mathrm{wt} . \%\right)$.

All these factors mentioned above can be explained by the effect of the cation nature on the water "structure" in its vicinity. It is common knowledge that water molecules, surrounding ionogenic groups of a polymer, behave differently than the ones inside the pure "water" associates. This type of hydrated water is well-ordered and is capable of forming clusters with a certain surface and shape [31]. Presumably, the processes of the existing hydrogen bonds degradation and the formation of the new ones in such clusters are responsible for the low endothermic effects, registered at 18$20^{\circ} \mathrm{C}$ on the DSC curves of air-dried powders of Na-CAS $(d H=-4 \mathrm{~J} / \mathrm{g})$ and $\mathrm{K}$-CAS $(d H=-3 \mathrm{~J} / \mathrm{g})$. At the same temperature, the endothermic effects with higher absolute values ( $d H$ from -6 to $-11 \mathrm{~J} / \mathrm{g}$ ) have been also found for the Na-CAS solutions containing from 42 to $58 \mathrm{wt} . \%$ of the polymer. The formation of LC phase takes place exactly within that concentration range (Table 5). We believe the formation of LC structures of the polyelectrolyte studied can be considerably affected by different types of water "packing" inside the clusters which either favour the polymer selfordering upon reaching the specific solution concentration
TABLE 5: Characteristics of endothermic effect registered on the NaCAS solutions' DSC curves.

\begin{tabular}{lcccc}
\hline $\begin{array}{l}\text { Solution con- } \\
\text { centration, } \\
\text { wt.\% }\end{array}$ & $d H, \mathrm{~J} / \mathrm{g}$ & $T_{i},{ }^{\circ} \mathrm{C}$ & $T_{p},{ }^{\circ} \mathrm{C}$ & $T_{f},{ }^{\circ} \mathrm{C}$ \\
\hline 42 & 7 & 15.2 & 18.9 & 25.0 \\
50 & -10 & 15.7 & 19.2 & 26.5 \\
52 & -6 & 16.0 & 19.2 & 24.7 \\
58 & -11 & 16.3 & 20.3 & 27.7 \\
\hline
\end{tabular}

(e.g., for $\mathrm{Li}, \mathrm{Na}$, and $\mathrm{Ca}$ salts) or impede this process (as for $\mathrm{K}$-CAS). For instance, the endothermic peak observed on the DSC curves of the Na-CAS solutions can be attributed to the partial degradation of the well-ordered LC domains owing to the increase in the mobility of water molecules inside the hydrated shells of polymeric ions. Particularly, the multifold increase of the $d H$ value (from -11 to $-77 \mathrm{~J} / \mathrm{g}$ ) found for $58 \mathrm{wt} . \% \mathrm{Na}$-CAS solution, preliminary heated up to $60^{\circ} \mathrm{C}$ and then cooled to $18^{\circ} \mathrm{C}$, indicates that endothermic effect depends on the degree of the solution anisotropy. A polarized light microscopy study of this solution specimens (58 wt.\%) and the Na-CAS solution that has not been subjected to the similar thermal cycle, showed that the volume fraction of LC phase is significantly higher in the first case. Similar results have been reported in publications [32, 33] by Japanese scientists that conducted DSC study of cellulose sulfate solutions.

It can be assumed that the ability of one or another CAS salt to form LC phase, in addition to well-known criteria, is directly related to the degree of water molecules structuring in the vicinity of the cation. According to the model, proposed by Frank and Evans [34] and Rabinovich [35], three layers can be distinguished in the surroundings of solvated ion, depending on the state of water molecules located within these layers. At first, zone A of "frozen" (structured) water in which the bonding between ions and water molecules is stronger than between water molecules in the absence of those ions; second, zone B of "disordered" (destructured) water in which water molecules undergo orientating effects (approximately equal in value but opposite in direction) from the adjacent water molecules and from the ion; finally, zone $\mathrm{C}$ in which water retains its own natural structure.

Ions with a high charge density, such as $\left(\mathrm{Ca}^{2+}\right)$ and single-charged small ions $\left(\mathrm{Li}^{+}, \mathrm{Na}^{+}\right)$, are characterized by strengthening of water structure beyond the first hydration layer, that is, the extension of zone A at the expense of zone B. This favours the stable hydrates formation and the well-ordered association of CAS molecules leading to the transition into LC state. The interaction of low charge density ions (large single-charged ions like $\mathrm{K}^{+}$) with water molecules can turn out to be comparatively weak even in the first hydration layer, so that the zone B of "destructured" water extends at the expense of zone A. Hence, due to the so-called "negative" hydration of potassium ions the degree of macromolecules convergence is low and selfordering becomes impossible, and as a result LC structures are not formed. The degradation effect of potassium ions 


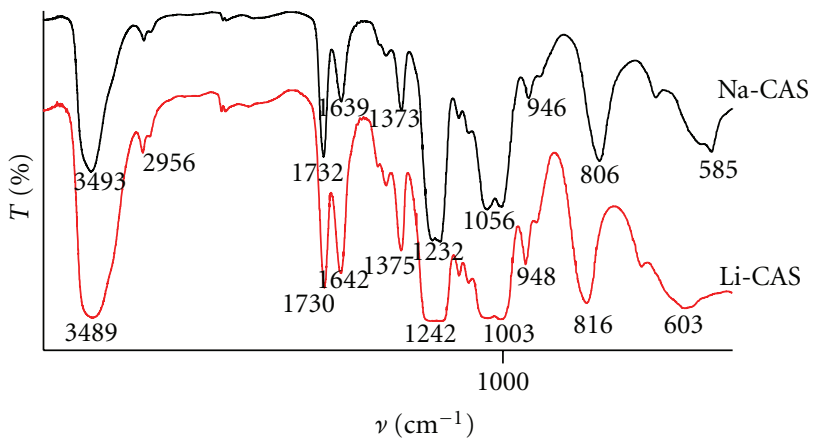

FIGURE 8: IR spectra of Li- and Na-CAS.

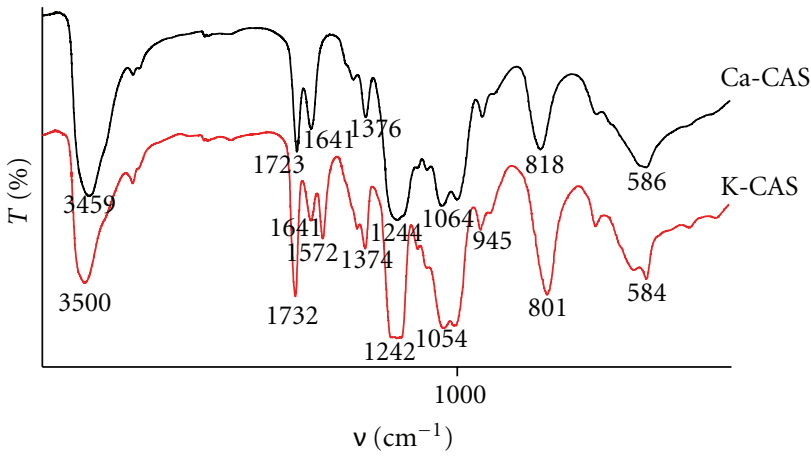

Figure 9: IR spectra of K- and Ca-CAS.

on the structure of water can also be indirectly determined from IR spectra of CAS salts (Figures 8 and 9). Thus, two peaks related to "combined" water $v=1641$ and $v=$ $1572 \mathrm{~cm}^{-1}$, instead of one $\left(v=1639-1640 \mathrm{~cm}^{-1}\right)$, have only been registered in the IR spectrum of K-CAS. According to the data published in $[28,36]$, a lower frequency of $\mathrm{H}-$ $\mathrm{O} \cdots \mathrm{H}$ grouping deformation vibration $\left(1550-1570 \mathrm{~cm}^{-1}\right)$ as compared to the frequency of the same vibration of individual water molecules is due to the fact that $\mathrm{OH}$ group does not form hydrogen bonds with other water molecules in its surroundings. IR spectra were measured with a spectrophotometer "FT-IR Spectrum 1000" (Perkin Elmer). The samples were prepared as films with the thickness of 3$7 \mu \mathrm{m}$.

To sum up, it has been found that the CAS salts thermal stability changes in the following series: Li-CAS $<\mathrm{Na}-\mathrm{CAS}<$ $\mathrm{K}-\mathrm{CAS}<\mathrm{Ca}-\mathrm{CAS}$. The analysis of TGA, DTG, DSC, and IR spectroscopy data allowed us to assume that along with the sorbed water (which is easily removed upon heating) the CAS salts also contain "structurally combined" water. The degree of ordering of this water in the counter-ions surrounding determines the feasibility of LC transition in the concentrated CAS salts solutions.

3.2. Phase Equilibria in Cellulose Acetate Sulfate-WaterAlcohol Systems. Reliable prediction and regulation of polymers solutions properties is possible when complete solubility diagrams are available. We have found that anhydrous

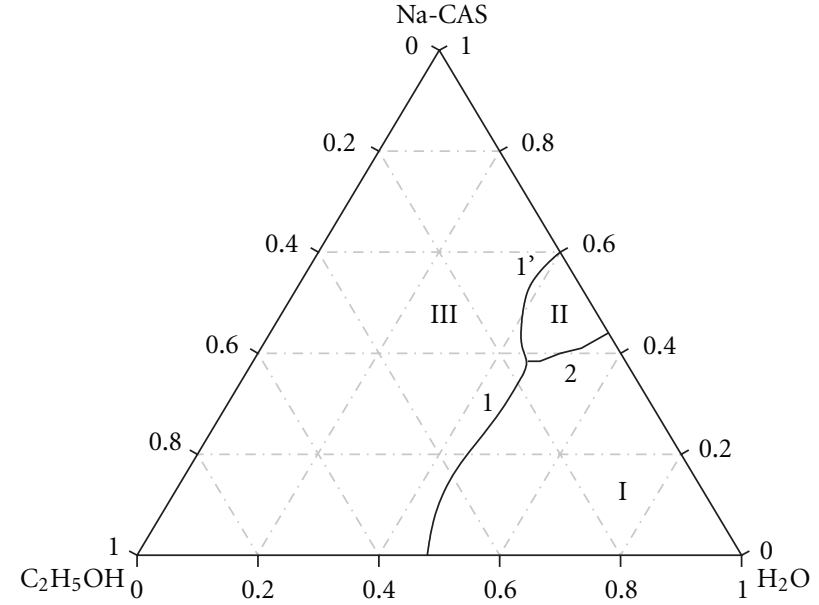

Figure 10: Solubility diagram of Na-CAS in water/ethanol at $18^{\circ} \mathrm{C}$.

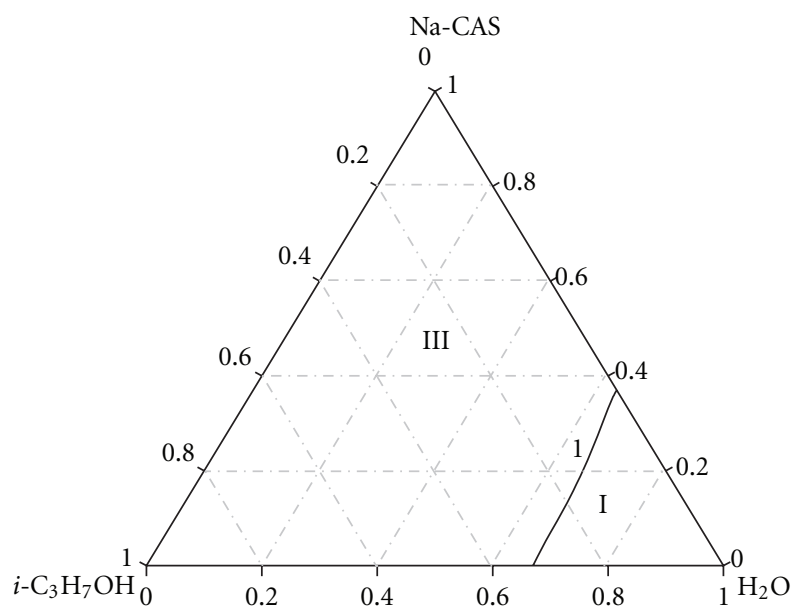

FIGURE 11: Solubility diagram of Na-CAS in water/isopropanol at $18^{\circ} \mathrm{C}$.

monohydric alcohols are precipitants, and their mixtures with water (at certain volume fractions) are solvents in the relation to the CAS. While the polymer was soluble in water/monohydric alcohol mixtures only in narrow composition range, it occurred virtually at any proportions of the components in water/polyhydric alcohol mixtures. The examination of the specimens in polarized light indicated the formation of either truly homogeneous solutions or solutions, containing LC structures and particles of nondissolved polymer, depending on the solvent composition and polymer content in the systems studied.

The results are represented in the forms of isothermal diagrams of the CAS solubility in water-alcohol media (Figures 10 and 11). There are the following areas: (I) the isotropic solution area, (II) the area of the isotropic solution and LC structures coexistence, and (III) the area of a heterogeneous system formed when the polymer is completely insoluble. Herewith, line 1 is the curve of the $\mathrm{Na}-\mathrm{CAS}$ solubility in the water-alcohol mixture; line 1 is a border between the area of LC solution and the area of 
heterogeneous system; line 2 separates the region of isotropic solutions from the region of isotropic and anisotropic phase mixture, that is, reflects the solution phase separation borderline.

$\mathrm{Na}$-CAS/Water/Ethanol System. It follows from Figure 9 that the polymer concentration of its highest solubility in this mixture consistently decreases as the ethanol quantity increases. At the alcohol content of more than $52 \mathrm{wt} . \%$, the Na-CAS ceases to be dissolved. This results in the appearance of a limited components miscibility area (III) on the solubility diagram. The isotropic solution area (I) corresponds to the polymer concentration from 0 to $42 \mathrm{wt} . \%$ at water/ethanol ratio of $48 / 51-100 / 0 \mathrm{wt} . \%$ Polarizing microscopy examination showed that the formation of supramolecular structures of LC nature takes place at the polymer concentration above $42 \mathrm{wt} . \%$ (area (II)).

$\mathrm{Na}$-CAS/Water/Isopropanol System. Like ethanol, anhydrous isopropanol is a precipitant for the Na-CAS. It only dissolves $\mathrm{Na}-\mathrm{CAS}$ when mixed with water in the compositions range of $100: 0-68: 32$ wt.\% (Figure 11). The area of homogeneous solution (I) on the triangle plane is significantly smaller than the one for water/ethanol mixture, and the area of LC solution (II) was not detected at all. This can be explained by a lower affinity of isopropanol, which is less polar than ethanol (dielectric constant $\varepsilon_{\text {isopropanol }}=18.3$ against $\varepsilon_{\text {ethanol }}=25.2$ ), towards the Na-CAS. For this reason, the highest polymer concentration at which solution remains homogeneous in this aqueous-alcoholic solvent comes to $35 \mathrm{wt} . \%$ only. This amount is not sufficient for LC state to be formed.

System $\mathrm{Na-CAS/Water/Glycerol.} \mathrm{Na-CAS} \mathrm{is} \mathrm{insoluble} \mathrm{in}$ anhydrous glycerol as in monohydric alcohols considered above. It is, however, highly soluble in water/glycerol mixtures at any other components ratios but $0: 100 \mathrm{wt} . \%$ (Figure 12).

Much larger area of infinite miscibility of the components (I) for system containing trihydric alcohol probably can be explained by a higher value of glycerol dielectric constant $\left(\varepsilon_{\text {gly }}=42.4\right)$ in comparison with the latter for ethanol and isopropanol. Na-CAS solutions in water/glycerol mixtures with the components ratios of $100: 0-55: 45 \mathrm{wt} . \%$ are liquid crystalline at polymer concentration from 42 to $57 \mathrm{wt} . \%$. At $\mathrm{Na}$-CAS content higher than $57 \mathrm{wt} . \%$ the system becomes heterogeneous and is characterized by the presence of nondissolved polymer particles along with LC structures. It should be emphasized that in water/glycerol solutions a much wider set of well-ordered structures have been formed. These includes not only individual spherulites but spherulite ribbons and "fingerprint" structures as well. In 50-52 wt.\%, $\mathrm{Na}$-CAS solutions stored overnight at $5^{\circ} \mathrm{C}$ the formation of a new phase in the form of needle-like crystals $0.5-1.0 \mathrm{~cm}$ long and containing up to $90 \mathrm{wt} . \%$ of solvent, took place. As soon as the LC state was registered in water/ethanol and water/glycerol mixtures, and there was no sight of it in water/isopropanol, the water-alcoholic-diluted solutions

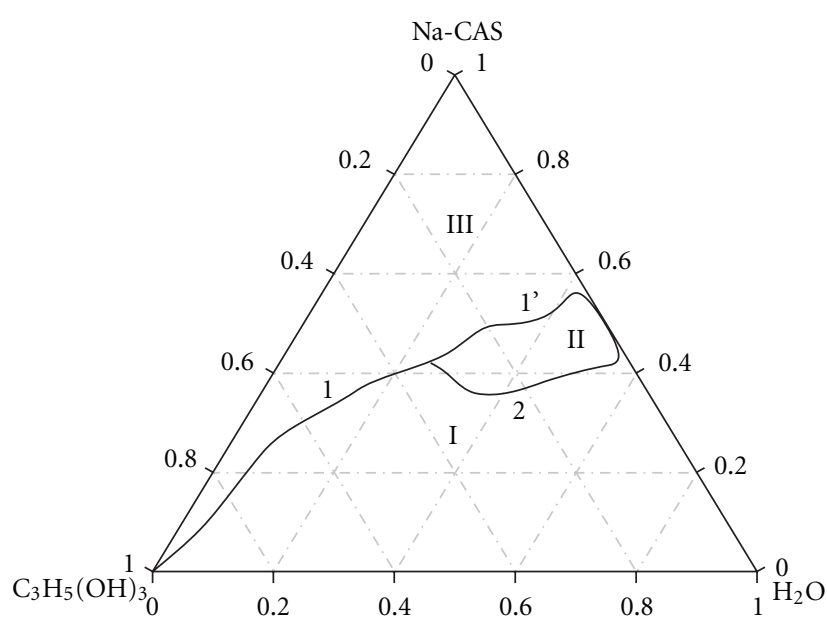

Figure 12: Solubility diagram of Na-CAS in water/glycerol at $18^{\circ} \mathrm{C}$.

of CAS have been chosen as models, convenient to test the criterion predicting mesophase emergence in concentrated solutions.

\subsection{Hydrodynamic Characteristics of Cellulose Acetate Sulfate} in Aqueous-Alcoholic Media. Hydrodynamic properties of Na-CAS dilute solutions have been studied both in the region of bicomponent solvent compositions where polymer demonstrates LC ordering and in the region where LC state has not been detected. Table 6 lists the experimentally estimated data such as intrinsic viscosity $[\eta]$, Huggins constant $k_{H}$ and crossover concentration $c_{\mathrm{cr}}$, as well as calculated parameters, characterizing the rigidity of polymer chain, namely, the Kuhn segment lengths $A$ and its axialratio $\varphi_{2 \text { calc }}$ of $\mathrm{Na}$-CAS depending on the alcohol content $Q$ in aqueous-alcoholic media. As it follows from calculations the volume polymer fraction $\varphi_{2 \text { calc }}$, where the LC phase begins to form, increases upon the addition of alcohol to the aqueous Na-CAS solutions. The polarized microscopy experimental data indicated that the polymer volume fraction $\varphi_{2 \exp }$, at which well-ordered formations are registered initially, equals 0.30 for all three type of aqueous-alcoholic systems and virtually has not been affected as the volume content of alcohol increased.

Mesophase formation has not been observed at all in water-isopropanol media, with the value of the highest $\mathrm{Na}$ CAS solubility $C_{\max }=35 \mathrm{wt} . \%\left(\varphi_{2}=0.24\right)$ being much lower than the critical value $\varphi_{2 \text { calc }}$.

The value of intrinsic viscosity decreases from 0.52 to $0.45\left(100 \mathrm{~cm}^{3} / \mathrm{g}\right)$ and from 0.54 to $0.31\left(100 \mathrm{~cm}^{3} / \mathrm{g}\right)$ as the content of ethanol and isopropanol, respectively, increases from 5 to 30 vol.\%. Since monohydric alcohols are precipitants of $\mathrm{Na}$-CAS this tendency can be explained by the solvent quality decline. The opposite trend is observed in water-glycerol mixtures: the increase of the intrinsic viscosity up to $0.61\left(100 \mathrm{~cm}^{3} / \mathrm{g}\right)$ when adding 50 vol.\% of glycerol. Although anhydrous glycerol, like monohydric alcohols, does not dissolve $\mathrm{Na}-\mathrm{CAS}$, it cannot be considered as a precipitant of the polymer. Presumably, trihydric alcohol is practically 
TABLE 6: Solvent composition effect on the hydrodynamic characteristics and the parameters of thermodynamic polymer chain rigidity of $\mathrm{Na}-\mathrm{CAS}$ in aqueous-alcoholic media.

\begin{tabular}{|c|c|c|c|c|c|c|c|c|}
\hline$Q$, vol. \% & {$[\eta], 100 \mathrm{~cm}^{3} / \mathrm{g}$} & $k_{H}$ & $c_{\mathrm{cr}}, \mathrm{g} / 100 \mathrm{~cm}^{3}$ & {$[\eta] \cdot k_{H} \cdot c_{\mathrm{cr}}$} & $A, \AA$ & $x$ & $\varphi_{2 \mathrm{calc}}$ & $\mathrm{LC}^{*}$ \\
\hline 0 & 0.44 & 0.66 & 1.70 & 0.49 & 220 & 29 & 0.26 & + \\
\hline \multicolumn{9}{|c|}{ Ethanol } \\
\hline 5 & 0.52 & 0.58 & 2.28 & 0.81 & 170 & 22 & 0.33 & + \\
\hline 10 & 0.46 & 0.71 & 2.55 & 0.83 & 160 & 21 & 0.34 & + \\
\hline 20 & 0.45 & 0.54 & 3.80 & 0.92 & 120 & 16 & 0.47 & + \\
\hline 30 & 0.45 & 0.40 & 6.05 & 1.09 & 80 & 10 & 0.64 & - \\
\hline \multicolumn{9}{|c|}{ Isopropanol } \\
\hline 5 & 0.54 & 0.60 & 3.50 & 1.13 & 130 & 17 & 0,42 & - \\
\hline 10 & 0.50 & 0.62 & 5.43 & 1.68 & 90 & 12 & 0,83 & - \\
\hline 20 & 0.45 & 0.74 & 7.87 & 2.62 & 70 & 9 & 0,69 & - \\
\hline 30 & 0.31 & 1.25 & & precipitation & red at & $00 \mathrm{cn}$ & & \\
\hline \multicolumn{9}{|c|}{ 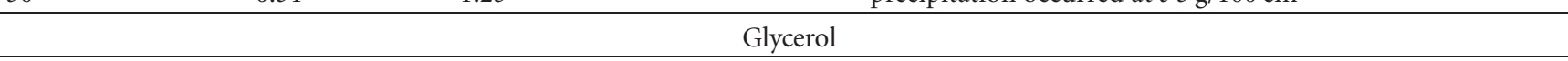 } \\
\hline 10 & 0.57 & 0.81 & 1.90 & 0.88 & 200 & 26 & 0.29 & + \\
\hline 50 & 0.61 & 0.39 & 8.80 & 2.09 & 60 & 8 & 0.75 & - \\
\hline
\end{tabular}

a solvent towards Na-CAS because the cellulose derivative becomes completely soluble in the presence of as little as $1 \mathrm{vol} . \%$ of water in the system.

The size of macromolecular coils in the solvent can be estimated by the intrinsic viscosity. However, the absolute numeric values of this parameter cannot be used to reliably predict the approach of the system to the state of LC ordering. Indeed, it might be suggested that the interval of intrinsic viscosity $[\eta]=0.57-0.44\left(100 \mathrm{~cm}^{3} / \mathrm{g}\right)$, corresponding LC state detection if $\mathrm{Na}$-CAS dissolved in water, water/glycerol ( 90 : 10 vol.\%) and water/ethanol (95:5-80:20 vol.\%), indicates whether the well-ordered structures formation takes place in the solution. However, within the same $[\eta]$ values range for water/isopropanol system, mesomorphism does not occur at all in concentrated solutions. The LC state has not been detected in $\mathrm{Na}$-CAS water/glycerol solutions containing 50 or more vol.\% of glycerol, although its $[\eta]$ value appeared even higher: $0.61\left(100 \mathrm{~cm}^{3} / \mathrm{g}\right)$.

Indirect conclusions about thermodynamic affinity of solvent towards the polymer can be drawn from Huggins viscometric constant $k_{H}$ values. The interpretation of this parameter in the literature is quite ambiguous $[37,38]$. We deem that for cellulose and its derivatives $k_{H}$ characterizes not so much "polymer-solvent" as "polymer-polymer" interactions, which should correlate with the amount of intramolecular hydrogen bonds. The lower the $k_{H}$ value, the higher the degree of multiple hydrogen bonds breaking in the cellulose chain. However, as it follows from Table 6 the Huggins constant is a nonmonotone function of the alcohol volume content. For instance, although the $k_{H}$ value increases in the systems, containing isopropanol, it sharply falls in water/glycerol mixtures as the alcohol content rises. There is also no direct correlation between absolute values of $k_{H}$ and the system ability to experience LC ordering.
For example, at $k_{H}=0.54-0.68 \mathrm{LC}$ ordering appears in the $\mathrm{Na}$-CAS/water/ethanol system whereas in the $\mathrm{Na}$ CAS/water/isopropanol at $k_{H}=0.60$ (that is in the same interval of the $k_{H}$ values), lyotropic phase is not formed.

Lastly, the crossover concentration $c_{\mathrm{cr}}$ is the polymer concentration at which statistical macromolecular coils begin to overlap, penetrating into each other. The lower the $c_{\mathrm{cr}}$ value, the lower the degree of macromolecules salvation, and, therefore, the contacts between them are more likely. It follows from Table 6 that the $c_{\mathrm{cr}}$ values increase as the alcohol volume content in the dissolving system grows. This can be an indicative of a decrease in the size of macromolecular coils caused by thermodynamic quality deterioration of bicomponent solvents, when their composition changes, resulting in the beginning of intermacromolecular contacts at the higher polymer concentration.

The calculated length of the Kuhn segment $A$ and the axial ratio $x$ values also decrease as the alcohol concentration grows and, besides, this tendency is the most noticeable for Na-CAS solutions in water/isopropanol. Herewith, the polymer chain rigidity decreases more than threefold compared to the one in the systems, containing no isopropanol. However, in this case, as for $[\eta]$ and $k_{H}$, there is no correlation between $c_{\mathrm{cr}}, A$ and $x$ values and the fact of LC phase formation in the concentrated solutions.

Thus, a comparative analysis of the isothermal Na-CAS solubility diagrams (at water/alcohol volume ratios listed in Table 6) with its hydrodynamic characteristics $\left([\eta], k_{H}, c_{\mathrm{cr}}\right)$ and chain rigidity ( $A$ and $x$ ) showed that the numeric value of each individual parameter alone cannot be used to predict the possibility of macromolecules orientational ordering in the concentrated polymer solutions. For this purpose, we are suggesting to use a product of intrinsic viscosity $[\eta]$, Huggins constant $k_{H}$ and crossover concentration $c_{\mathrm{cr}}$, 
TABLE 7: Hydrodynamic characteristics of CAS salts aqueous solutions and parameters of polymer chain rigidity.

\begin{tabular}{lcccccccc}
\hline Counterion & {$[\eta], 100 \mathrm{~cm}^{3} / \mathrm{g}$} & $k_{H}$ & $c_{\mathrm{cr}}, \mathrm{g} / 100 \mathrm{~cm}^{3}$ & {$[\eta] \cdot k_{H} \cdot c_{\mathrm{cr}}$} & $A, \AA$ & $x$ & $\varphi_{2 \mathrm{calc}}$ & $\mathrm{LC}$ \\
\hline $\mathrm{Li}^{+}$ & 0.72 & 0.25 & 1.77 & 0.32 & 200 & 26.7 & 0.28 \\
$\mathrm{Na}^{+}$ & 0.44 & 0.66 & 1.70 & 0.49 & 220 & 28.5 & 0.26 \\
$\mathrm{~K}^{+}$ & 0.66 & 0.55 & 3.84 & 1.39 & 120 & 15.8 & 0.44 \\
$\mathrm{Ca}^{2+}$ & 0.47 & 0.32 & 1.84 & 0.28 & 240 & 29.5 & 0,25 \\
$\mathrm{Mg}^{2+}$ & 0.42 & 0.40 & 1.85 & 0.31 & 220 & 27.7 & 0.26 \\
$\mathrm{Zn}^{2+}$ & 0.44 & 0.52 & 2.16 & 0.49 & 230 & 27.3 & 0.27 \\
$\mathrm{Co}^{2+}$ & 0.42 & 0.62 & 2.30 & 0.60 & 220 & 24.8 & 0.30 \\
\hline
\end{tabular}

* Note

"+"-LC phase was formed.

“_”-LC phase was not formed.

TABLE 8: Hydrodynamic characteristics of cellulose and its derivatives solutions as well as polyacrylic acid.

\begin{tabular}{|c|c|c|c|c|c|c|}
\hline Polymer & Solvent & {$[\eta], 100 \mathrm{~cm}^{3} / \mathrm{g}$} & $k_{H}$ & $c_{\mathrm{cr}}, \mathrm{g} / 100 \mathrm{~cm}^{3}$ & {$[\eta] \cdot k_{H} \cdot c_{\mathrm{cr}}$} & $\mathrm{LC}^{*}$ \\
\hline Cellulose & TFAA & 3.10 & 1.18 & 0.58 & 2.12 & - \\
\hline $\mathrm{AC}(\mathrm{DS}=1.5)$ & TFAA & 2.43 & 0.65 & 0.50 & 0.79 & + \\
\hline $\mathrm{AC}(\mathrm{DS}=2.5)$ & TFAA & 1.70 & 0.56 & 0.40 & 0.38 & + \\
\hline $\mathrm{AC}(\mathrm{DS}=2.5)$ & $\mathrm{CH}_{3} \mathrm{COCH}_{3}$ & 1.80 & 0.40 & 0.96 & 0.69 & + \\
\hline $\mathrm{AC}(\mathrm{DS}=2.9)$ & TFAA & 1.60 & 0.56 & 0.40 & 0.36 & + \\
\hline $\mathrm{AC}(\mathrm{DS}=2.9)$ & $\mathrm{CH}_{2} \mathrm{Cl}_{2}$ & 1.40 & 0.80 & 1.50 & 1.68 & - \\
\hline HPC & $\mathrm{H}_{2} \mathrm{O}$ & 2.80 & 0.86 & 0.34 & 0.82 & + \\
\hline $\mathrm{ABC}$ & DMAA & 1.80 & 0.51 & 0.20 & 0.18 & + \\
\hline $\mathrm{EC}$ & $\mathrm{CH}_{3} \mathrm{COOH}$ & 2.00 & 0.31 & 0.20 & 0.12 & + \\
\hline PAA & $\mathrm{H}_{2} \mathrm{O}-\mathrm{NaCl}$ & 3.20 & 0.32 & 2.05 & 2.10 & - \\
\hline
\end{tabular}

${ }^{*}$ Note

"+"-LC phase was formed.

which takes into account all main types of interactions occurred in the system: "polymer-polymer", "polymersolvent" and the degree of polymer macromolecules filling the unit of the solution volume [10]. This parameter is nondimensional, and its absolute value does not exceed 1 in the LC systems.

It should be noted, that this criterion distinctly predicts the LC formation for other CAS salts dissolved in water (Table 7).

The application of the empirical product $[\eta] \cdot k_{H} \cdot c_{\mathrm{cr}}$ to the solutions of nonionogenic cellulose derivatives and synthetic polyelectrolyte: polyacrylic acid (PAA), in order to predict whether the polymer-solvent system can have lyotropic mesomorphism, appeared to be possible (Table 8). Indeed, the LC state has been registered in the AC (DS = 2.9) dissolved in TFAA $\left([\eta] \cdot k_{H} \cdot c_{\mathrm{cr}}=0.36\right)$ and in the aqueous HPC solutions $\left([\eta] \cdot k_{H} \cdot c_{\mathrm{cr}}=0.82\right)$, but it has not been detected in the systems like AC (DS = 2.9) $-\mathrm{CH}_{2} \mathrm{Cl}_{2}$ $\left([\eta] \cdot k_{H} \cdot c_{\mathrm{cr}}=1.68\right)$ and PAA- $\mathrm{H}_{2} \mathrm{O}\left([\eta] \cdot k_{H} \cdot c_{\mathrm{cr}}=2.10\right)$.

To summarize, the analysis of hydrodynamic characteristics of CAS dissolved in aqueous-alcoholic media has showed, that the empirical parameter $[\eta] \cdot k_{H} \cdot c_{\text {cr }}$ allows to predict an ability to prepare concentrated LC solutions of cellulose derivatives.

\section{Application of Cellulose Acetate Sulfate}

Owing to high water solubility of Na-CAS, its ability to form LC structures in the concentrated solutions, this polymer can be recommended as a new auxiliary substance-modificator for production of readymade medicinal forms.

Preclinical toxicological studies of the Na-CAS have been conducted in order to estimate safety of its practical application. The polymer has been established to have an extremely low toxicity (lethal dose (LD50) has not been found) and it is harmless to animals. It does not have mutogenous, skin irritating and allergenic activity, therefore, it does not have any usage limitations as a pharmaceutical component in medications.

The studies show that the technological regulation for Na-CAS production has been developed. The pilot plant with the $500 \mathrm{t} /$ year capacity has been designed and tested at Republican Unitary Enterprise (Svetlogorsk Production Association "Khimvolokno") (Svetlogorsk, Belarus).

4.1. New Quickly Dispersed Active Carbon Tablets. Owing to the physical adsorption of polymer macromolecules on the carbon particles surface, modification of activated carbon (AC) with CAS confers a unique combination of properties 


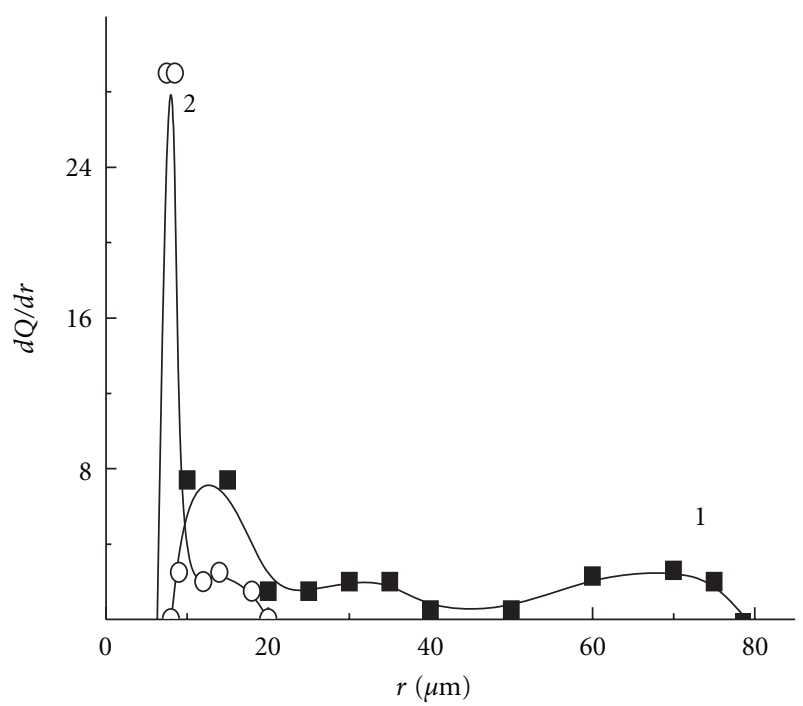

Figure 13: Differential curves of the particle-size distributions for suspensions of the initial carbon (1) and modified with the Na-CAS (2) at $20^{\circ} \mathrm{C}$ in the aqueous medium.

to it, like an ability to disperse in water spontaneously and quickly, forming stable suspensions with narrow particles size distribution and with high content of micro- and submicroparticles (Figure 13). The suspensions of the modified carbon have high fluidity, Newtonian character of the flow and hence the minimal structure formation in wide concentration ranges, significant specific surface, and adsorption activity towards substances of different origin (Figure 14). The stabilizing effect and that of CAS is due to its high affinity to water and hence high hydrophilization of carbon particles. In this case, along with the structural-mechanical factor, the electrostatic factor of aggregation stability can also play a specific role. These colloid-chemical characteristics of the carbon suspensions allowed us to recommend $\mathrm{Na}$-CAS as a binder for obtaining both quickly soluble solid medicinal forms of $\mathrm{AC}$ and effective preparations for contaminated water purification.

"Uglesorb" Tablets. The tablets are suitable for administration and unlike their AC powder forms do not cause tickles in the throat, belching, retching, and so forth.

As the drug is highly efficient the dose administered is decreased and the course of treatment is shortened several times. New enterosorbent is effective in treating allergies, in lessening postradiation damages, which have caused new malignant growths in the patients' thorax, in case of nazointestinal intubation in the postoperation treatment of peritonitis, and so on.

"Black Aspirin" Tablets. Quickly disintegrated "Black aspirin" tablets, containing acetylsalicylic acid (ASA), vitamin C, carbon, and Na-CAS have ballast fillers like citric acid and sodium bicarbonate, which cause additional irritation of gastrointestinal tract mucous because of gas evolution as opposed to the ones manufactured. Experimental tablets

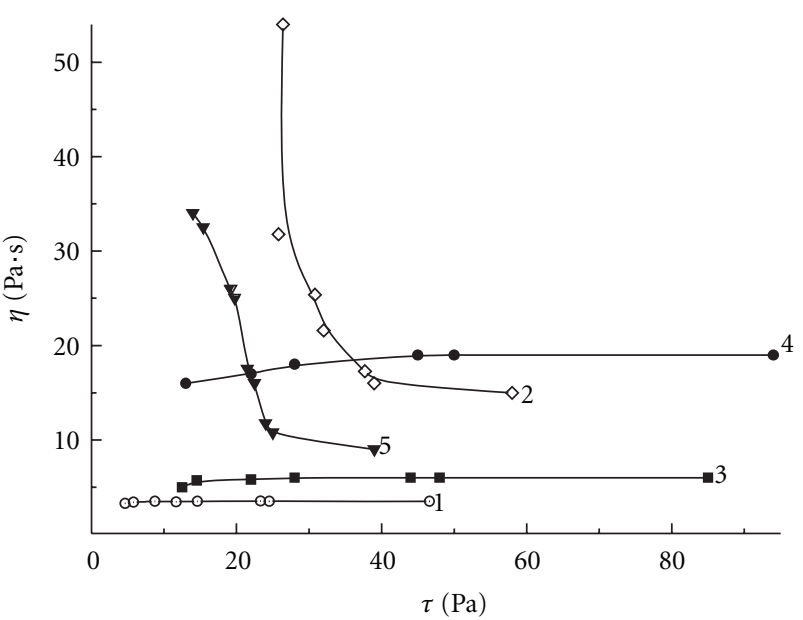

Figure 14: Viscosity versus shear stress for the 15 and 25\% aqueous suspensions of the initial activated carbon $(1,2)$ and activated carbon modified with the Na-CAS $(3,4)$, respectively, and of the $15 \%$ suspension of the activated carbon modified with the starch (5).

unlike common aspirin are dissolved spontaneously upon the contact with liquid media, forming highly dispersed suspensions, and have better dissolution kinetic (Figures 15 and 16). In these suspensions ASA crystals have round (not needle-like) shape and are surrounded by the colloid carbon particles, that prevent direct contact of ASA with the stomach and duodenum mucous membrane. The new tablets are characterized by the combination of quick-action and prolongation: the rate of ASA release is approximately 2.5 times and the accumulation time in blood is three times higher compared to the white tablets produced by "Bayer AG".

"Black Antacid" Tablets. These combined tablets, containing calcium carbonate and magnesium carbonate, have high acid-neutralizing ability. Unlike the renowned "Rennie", they have high neutralization reaction rate due to the $\mathrm{Na}$-CAS presence in the composition of "Black antacid" (Figure 17). This facilitates fast spontaneous dispersion of drugs and increases neutralizing agents' accessibility.

Veterinary Preparations. New combined preparations on the basis of AC modified with Na-CAS, chitosan, vitamins, and minerals have been designed to be used as nutrition for broilers and laying hens. It has a better assimilability compared to the preparations based only on individual components that improves biological value of hen's eggs and broiler's meat.

4.2. Highly Hydrophilic Ointments Containing Cellulose Acetate Sulfate. Needs of modern medicine in the field of ointment preparations cannot be met only by new medicinal substances' synthesis. Recently, a trend in the pharmaceutical industry, considering the conferring of new pharmacological and pharmacokinetic properties to well-known drugs with the aid of new auxiliary compounds has been 


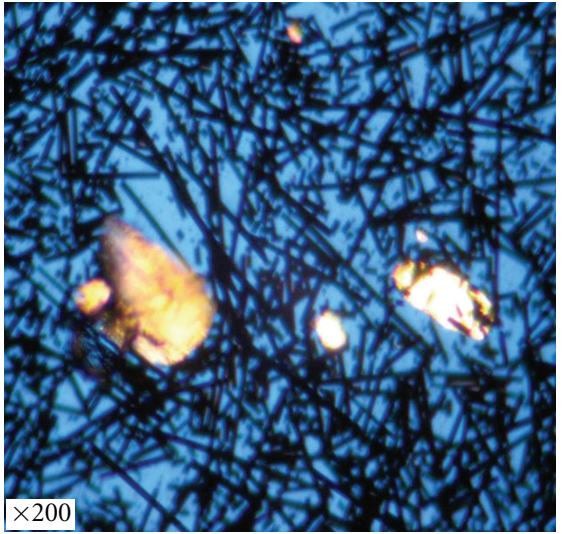

(a)

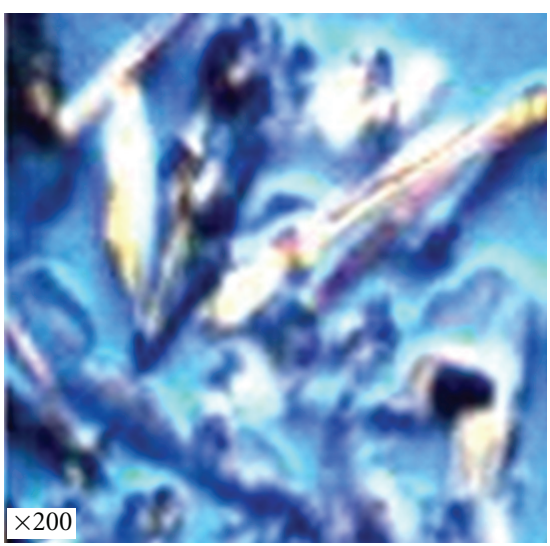

(b)

FIGURE 15: Photographs of ASA microparticles in different tablets.

quickly developing. The study of Na-CAS application for preparation of new highly hydrophilic ointments has been conducted in the same direction. Hydrophilic foundations as opposed to lypophilic ones provide a homogeneous introduction of a significant amount of water and watersoluble medicinal preparations into ointment compositions. Hydrophilic ointments have the following advantages: low structural strength, ability to a thixotropic dilution upon the mechanical effect, they are easily absorbed by skin, quickly release medicinal substances, and convenience in application.

The conducted studies have shown that CAS compatibility with various substances: water-soluble antibiotics (like lincomycin, gentamicin, bensilpenicillin, diclofenac, etc.), low-molecular-weight homologues of polyethylene oxide, highmolecular-weight compounds (like chitosan, methylcellulose, carboxylmethylcellulose, hydroxymethylcellulose, and polyacrylic acid).

Besides ointments solutions on Na-CAS basis, ointments suspensions, containing zinc oxide, $\mathrm{AC}$, and prednisolone acetate along with antibiotics of aminoglycoside type, have been prepared as well. Microscopic dispersed analysis has demonstrated that the disparity degree of medicinal substances insoluble in water increases 2-15 times when using

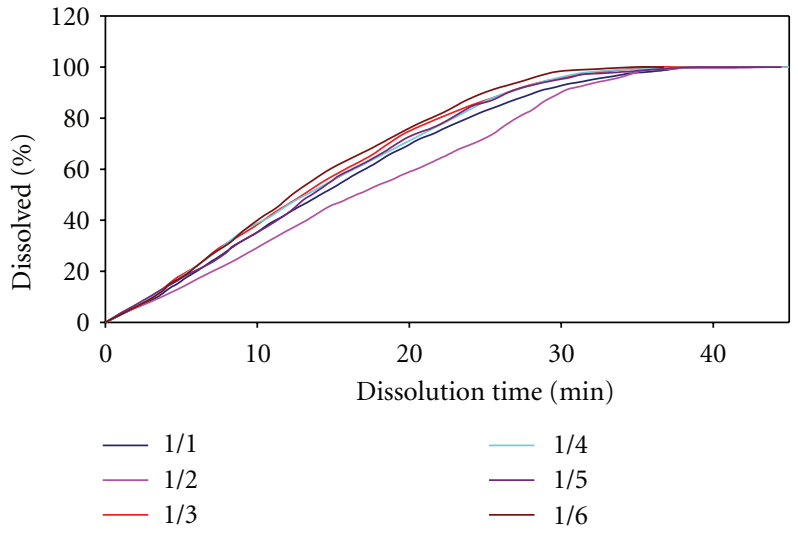

(a) Single dissolution tests

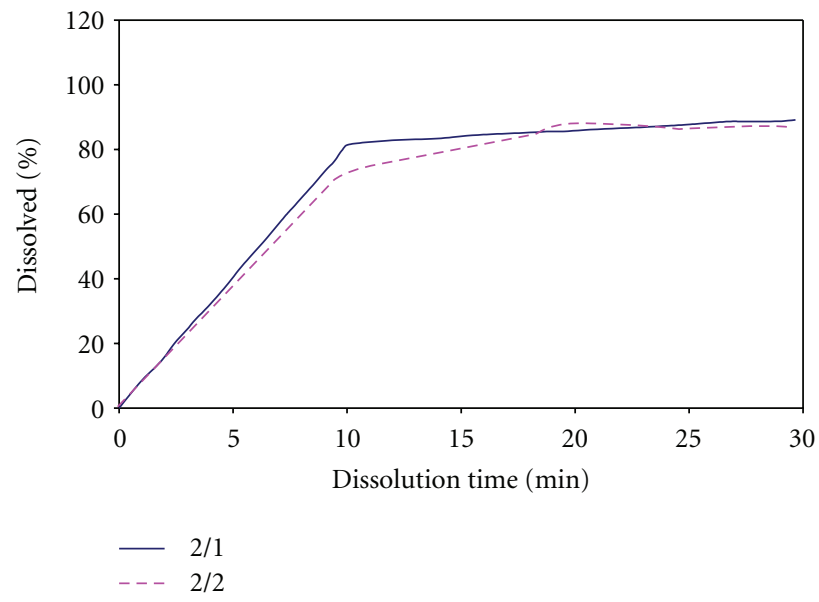

(b) Single dissolution tests

FIGURE 16: Release kinetics of acetylsalicylic acid from Bayer aspirin tablets (1) and "Black aspirin" tablets (2) (Data of Bayer AG).

CAS. This leads to a significantly higher homogeneity of their distribution in the ointment volume and provides the aggregative stability of the ointment suspension for as long as two years.

Clinical trials of the "Gel prednisolone 0.5\%" ointment based on the new hydrophilic foundation have been conducted. It has been found that the experimental ointment is not toxic and does not cause skin-irritation and allergy. Compared with the traditional ointments based on hydrophilic, adipose or combined hydrophilic-lypophilic foundations produced by pharmaceutical industry, high therapeutic efficiency and convenience of "Gel prednisolone $0.5 \%$ " application for dermatitis, eczema and psoriasis treatments have been distinguished.

At present the optimal compositions of hydrophilic ointment foundations and the ways of their compatibility with medicinal substances have been determined. The foundation compositions have been offered both for traditional use and the design of ointments having either prolongation (owing to a complex formation between CAS and medicinal substance) or combined activity (for instance, by combination of antibiotic and AC properties). They also have been proposed to design dry napkins, containing all components 
of hydrophilic ointments but water, suitable for treatment and surgery practices. New ointment foundations can be of significant interest not only for production of human drugs but preparations of veterinary purposes as well.

Currently, the temporary pharmaceutical articles on $\mathrm{Na}$ CAS (Cellulose acetate sulphate sodium salt, VFS RB 04902000) and individual medicinal preparations as the charcoal tablets ("Ultrasorb", VFS RB 42B-257-98; "Uglesorb", VFS RB 0491-2000) and the ointment ("Gel prednisolone 0.5\%", VFS RB 0535-2001) have been obtained. The Ministry of Health of the Republic of Belarus has permitted their industrial production.

4.3. Preparations "Dispersed Carbon Sorbent" and "Carbon Coagulant" for Water Treatment. We have developed tablets and granule forms of "Dispersed carbon sorbent" and "Carbon coagulant" based on a powder-like form of AC, modified with Na-CAS. They appeared to be suitable for treatment of water originating from contaminated sources and consequently for obtaining drinking water. The main feature of their activity consists in the buildup within a short period of time (3-15 min) of fine-dispersed suspensions of carbon particles, which can be aggregated into a sediment containing soil, organic, inorganic, and microbiological contaminants.

Joint application of these preparations a long with disinfecting tablets "Aquatabs" (which are the source of active chlorine) and specially designed multilayered filters provides a complex treatment of contaminated water by oxidation, sorption, coagulation, and filtration. The treated water completely corresponds to SanPiN (SanPiN 10-124 RB 99 is a normative of the Republic of Belarus that regulates drinking water standards.) 10-124 RB 99 "Drinking water" requirements. This type of treatment has been used while developing and manufacturing water treatment systems such as individual portable kits and mobile autonomous water purification plant (MAWPP).

Currently, Na-CAS and all the mentioned above products are certified against technical requirements of the Republic of Belarus (TR RB): TR RB 100050710.067-2003 “ Sodium salt of cellulose acetate sulfate"; TR RB 100050710.099-2006 "Dispersed carbon sorbent"; TR RB 100235722.128-2003 "Carbon coagulant"; TR RB 100235722.129-2003"Kit for the treatment of polluted surface and underground waters".

\section{Main Results}

(1) Homogeneous synthesis of CAS with the yield of 95-98 wt.\% has been developed. By means of the chemical analysis and NMR ${ }^{13} \mathrm{C}$ spectroscopy it was shown that the location of sulfate groups is at $\mathrm{C}_{6}$ position while acetate groups are located at $\mathrm{C}_{2}$ position of the CAS elementary unit.

(2) It has been established that the homogeneously synthesized CAS has properties of a strong polymeric acid. It is capable of effective ion exchange leading to a formation of stable salts, containing counter-ions of $\mathrm{Li}^{+}, \mathrm{Na}^{+}, \mathrm{K}^{+}, \mathrm{Ca}^{2+}$, $\mathrm{Mg}^{2+}, \mathrm{Zn}^{2+}$, and $\mathrm{Co}^{2+}$. The solubility and phase state of the CAS in aqueous, aqueous-organic and organic media were

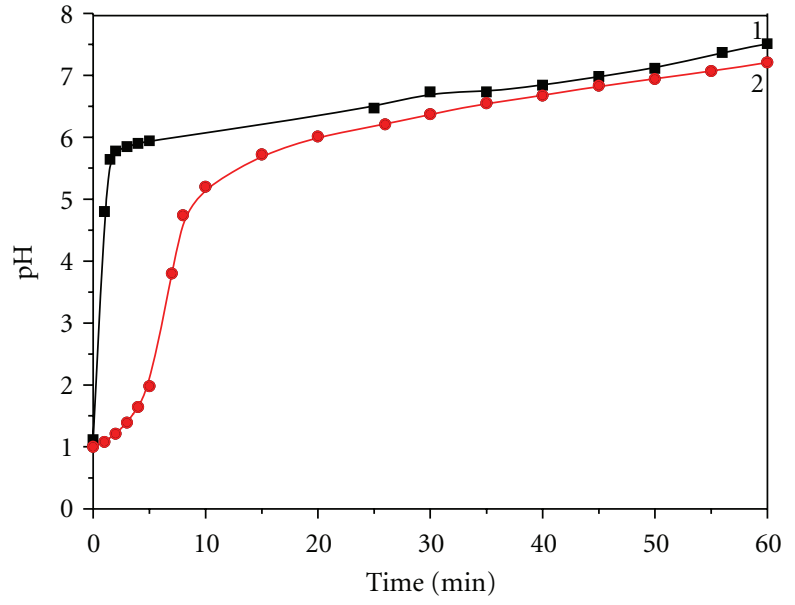

FIgURE 17: Kinetics of "Black antacid" (1) and "Rennie" (Switzerland) (2) interaction with $0.1 \mathrm{M} \mathrm{HCl}$

estimated in the wide range of components concentrations. All the CAS salts were completely soluble in water and watersalt media, while their solubility in aqueous-organic media was limited. The concentration of the maximum CAS salt solubility in water decreases as a radius of compensating counter-ion is rising in the following manner:

$$
\begin{gathered}
\text { Li-CAS }>\text { Na-CAS }>\text { Ca-CAS }>\text { K-CAS } \\
=70>60>55>52 \text { wt. } \%
\end{gathered}
$$

(3) For the first time the formation of highly organized LC structures has been registered in aqueous CAS solutions excepting potassium salt. The unambiguous confirmations of the concentrated CAS solution transition to LC state have been found. Rheological sign of the spontaneous LC ordering in concentrated CAS solutions was the extreme character of the viscosity dependency on concentration. It was shown that the critical concentration value, corresponding to the LC structures emergence in the CAS salts solutions, decreases as a cation radius increases.

(4) Based on the information obtained from thermal analysis and IR spectroscopy of the CAS salts, a hypothesis regarding a determinative role of water molecules from the close environment of the compensation counter-ion in the mechanism of LC phase formation was proposed.

(5) Values of intrinsic viscosity $[\eta]$, Huggins constant $k_{H}$ and crossover concentration $c_{\mathrm{cr}}$ have been estimated by means of viscometry method for the CAS salts in their water-alcohol and water-salt solutions. The workability of the empirical criterion $[\eta] \cdot k_{H} \cdot c_{\mathrm{cr}}$ predicting the possibility of LC state formation in the concentrated CAS solutions was confirmed. The demonstration of the lyotropic mesomorphism for a certain polymer-solvent system is possible when $[\eta] \cdot k_{H} \cdot c_{\mathrm{cr}}<1$. It was shown that this criterion is applicable to the other ionogenic and nonionogenic cellulose derivatives solutions for predicting purposes.

(6) The pilot plant production of Na-CAS has been developed, and the fields of its practical application have been 
proposed. CAS has been recommended as a suitable component both for the preparation of quickly dispersed tablets, granules and hydrophilic ointment drugs and for water treatment as well.

\section{References}

[1] D. D. Grinshpan, S. M. Tret'yakova, N. G. Tsygankova, S. E. Makarevich, and T. A. Savitskaya, "Phase equilibria in sodium salt of cellulose acetate sulfate-water-alcohol systems and a criterion of the formation of the liquid crystalline state," Russian Journal of Physical Chemistry A, vol. 79, no. 11, pp. 1728-1733, 2005.

[2] D. D. Grinshpan, S. M. Tret'yakova, N. G. Tsygankova, S. E. Makarevich, and T. A. Savitskaya, "Rheological studies of high-concentration cellulose sulfate-acetate solutions," Journal of Engineering Physics and Thermophysics, vol. 78, no. 5, pp. 878-884, 2005.

[3] T. A. Savitskaya, T. N. Nevar, and D. D. Grinshpan, "Simulation of the rheological behavior of enterosorbents in the gastroenteric tract in vitro," Journal of Engineering Physics and Thermophysics, vol. 78, no. 5, pp. 989-993, 2005.

[4] D. D. Grinshpan, N. G. Tsygankova, S. M. Tret'yakova, and T. A. Savitskaya, "The formation of a lyotropic mesophase in aqueous solutions of the sodium salt of cellulose acetate sulfate," Polymer Science - Series B, vol. 44, no. 1-2, pp. 23-26, 2002.

[5] T. A. Savitskaya, T. N. Nevar, and D. D. Grinshpan, "The effect of water-soluble polymers on the stability and rheological properties of suspensions of fibrous activated charcoal," Colloid Journal, vol. 68, no. 1, pp. 86-92, 2006.

[6] G. A. Petropavlovskij, Hydrophilic Partially Substituted Cellulose Ethers, Khimiya, Leningrad, Russia, 1988.

[7] V. I. Azarov, Chemistry of Wood and Synthetic Polymers: A Textbook for High Schools, SPb: SPbLTA, 1999.

[8] Z. A. Rogovin, Chemistry of Cellulose, Khimaya, Moscow, Russia, 1972.

[9] T. Heinze and T. Liebert, "Unconventional methods in cellulose functionalization," Progress in Polymer Science, vol. 26, no. 9, pp. 1689-1762, 2001.

[10] D. D. Grinshpan, Nonaqueous Cellulose Solvents, Universitetskoye, Minsk, Belarus, 1991.

[11] T. V. Ilichev, R. I. Feldman, and K. S. Nikolskij, Patent 2074194 (RU).

[12] E. D. Klug, Patent 2753337 (USA).

[13] R.G. Zhbankov, Physics of Cellulose and Its Derivatives, Nauka i tekhnika, Minsk, Belarus, 1983.

[14] T. I. Usmanov, "NMR spectroscopy comparative study of the substituents distribution in the cellulose acetates obtained in various ways," Khimiya Drevesini, vol. 5, pp. 81-87, 1987.

[15] K. Kamide, "Determination of distribution of sodium sulfate group in glucopyranose units of sodium cellulose sulfate by ${ }^{13} \mathrm{C}$ and ${ }^{1}$ Hnuclear magnetic resonance analysis," Polymer Journal, vol. 13, no. 2, pp. 163-166, 1981.

[16] M. Thomas, G. Chauvelon, M. Lahaye, and L. Saulnier, "Location of sulfate groups on sulfoacetate derivatives of cellulose," Carbohydrate Research, vol. 338, no. 8, pp. 761-770, 2003.

[17] K. Kowsaka, K. Okajima, and K. Kamide, "Determination of the distribution of substituent groups in sodium cellulose sulfate. Assignment of $\mathrm{H}$ and $\mathrm{C}$ NMR peaks by two-dimensional COSY and CH-COSY methods," Polymer Journal, vol. 23, no. 7, pp. 823-836, 1991.
[18] A. F. Samarin, "Viscosity boundary in dilute polymer solutions," Visokomol Soedin B, vol. 27, pp. 271-274, 1985.

[19] S. P. Papkov, "Phase equilibriums in polymer systems containing liquid crystalline phase," in Liquid Crystalline Polymers, N. A. Plate, Ed., vol. 2, pp. 43-47, Khimiya, Moscow, Russia, 1988.

[20] R. S. Werhowyj, "Liquid crystalline structure in aqueous hydroxypropylcellulose solutions," Molecular Crystals \& Liquid Crystals, vol. 34, pp. 97-103, 1976.

[21] V. G. Kulichihin, "Rheological properties of liquid crystalline polymer systems," Visokomol Soedin A, vol. 26, pp. 451-471, 1984.

[22] H. Chanzy, S. Nawrot, A. Peguy, P. Smith, and J. Chevalier, "Phase behavior of the quasiternary system nmethylmorpholine-n-oxide, water, and cellulose," Journal of Polymer Science Polymer Physics, vol. 20, no. 10, pp. 1909-1924, 1982.

[23] S. P. Papkov, Liquid Crystalline Polymers, Khimiya, Moscow, Russia, 1977.

[24] V.G. Kulichihin, "Liquid crystalline state of cellulose and its derivatives," Khimiya Drevesini, vol. 3, pp. 9-27, 1985.

[25] V. A. Belyakov, Optics of Cholesteric Liquid Crystals, Nauka, Moscow, Russia, 1982.

[26] N. I. Avakumov et al., Workshop on Chemistry and Physics of Polymers, Khimiya, Moscow, Russia, 2nd edition, 1990.

[27] G. A. Krestov et al., Ionic Solvation, Nauka, Moscow, Russia, 1987.

[28] V. N. Makatun, Chemistry of Inorganic Hydrates, Nauka i technika, Minsk, Belarus, 1985.

[29] S. P. Papkov, "Kuhn segment estimation of the rigid-chain polymers by dilute solutions viscosity properties," Vysokomol Soedin B, vol. 24, pp. 869-873, 1982.

[30] P. J. Flory, Principles of Polymer Chemistry, Cornell University Press, Ithaca, NY, USA, 1953.

[31] S. Roulend et al., Water in Polymers, Mir, Moscow, Russia, 1984.

[32] T. Hatakeyama, H. Yoshida, and H. Hatakeyama, "A differential scanning calorimetry study of the phase transition of the water-sodium cellulose sulphate system," Polymer, vol. 28, no. 8, pp. 1282-1286, 1987.

[33] T. Hatakeyama, H. Yoshida, and H. Hatakeyama, "The liquid crystalline state of water-sodium cellulose sulphate systems studied by DSC and WAXS," Thermochimica Acta, vol. 266, no. C, pp. 343-354, 1995.

[34] H. S. Frank and M. W. Evans, "Free volume and entropy in condensed systems III. Entropy in binary liquid mixtures; Partial molal entropy in dilute solutions; Structure and thermodynamics in aqueous electrolytes," The Journal of Chemical Physics, vol. 13, no. 11, pp. 507-532, 1945.

[35] V. A. Rabinovich, Thermodynamic Activity of Ions in Electrolyte Solutions, Khimiya, Leningrad, Russia, 1985.

[36] N. D. Sokolov, Hydrogen Bond, Nauka, Moscow, Russia, 1981.

[37] L. A. Udahina and A. V. Kuzmina, Methods of Determining the Limiting Viscosity Number, Ilim, Frunze, Russia, 1980.

[38] I. Dort, "On the possibility of quantitative evaluation of the polymer-solvent interaction from the Huggins viscosity constant," Polymer, vol. 29, no. 3, pp. 490-499, 1988. 

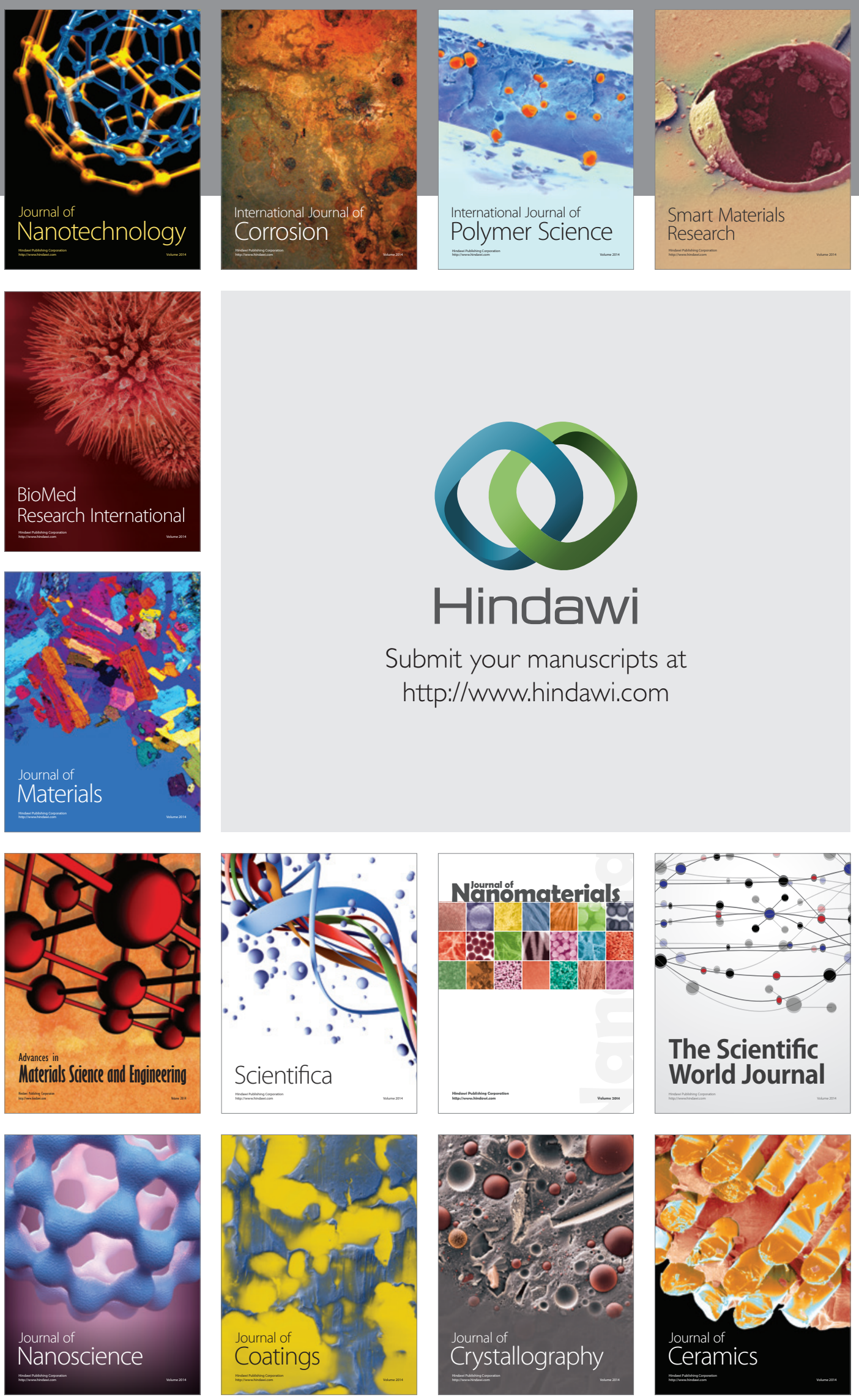

The Scientific World Journal

Submit your manuscripts at

http://www.hindawi.com

\section{World Journal}

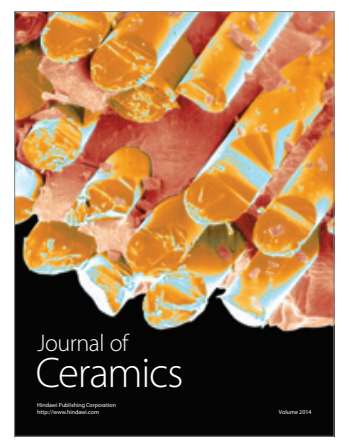

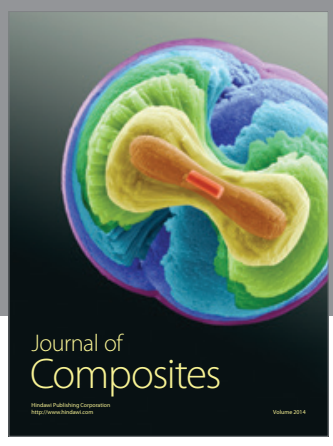
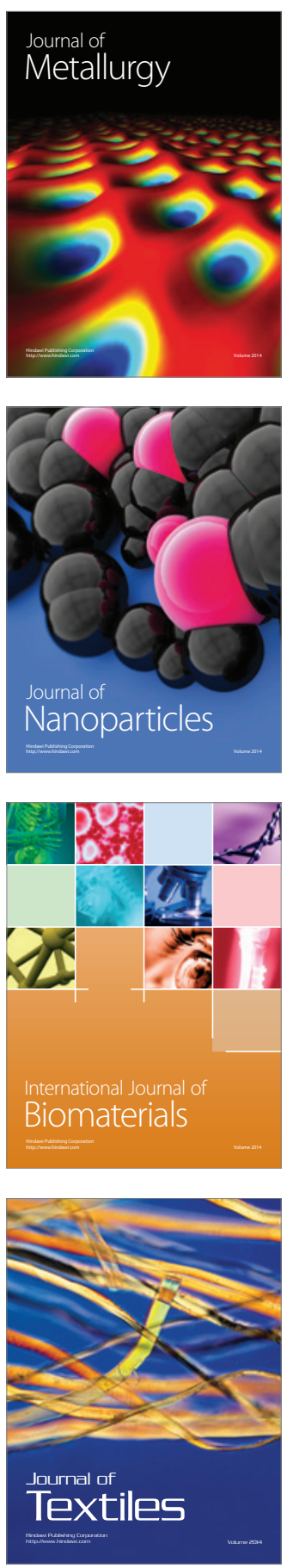